\title{
Technology readiness: a meta-analysis of conceptualizations of the construct and its impact on technology usage
}

\author{
Markus Blut ${ }^{1} \cdot$ Cheng Wang ${ }^{2}$ \\ Received: 19 April 2018 / Accepted: 19 July 2019 /Published online: 5 August 2019 \\ (C) The Author(s) 2019
}

\begin{abstract}
The technology readiness (TR) index aims to better understand people's propensity to embrace and use cutting-edge technologies. The initial TR construct considers four dimensions - innovativeness, optimism, insecurity, and discomfort - that collectively explain technology usage. The present meta-analysis advances understanding of TR by reexamining its dimensionality, and investigating mediating mechanisms and moderating influences in the TR-technology usage relationship. Using data from 193 independent samples extracted from 163 articles reported by 69,263 individuals, we find that TR is best conceptualized as a two-dimensional construct differentiating between motivators (innovativeness, optimism) and inhibitors (insecurity, discomfort). We observe strong indirect effects of these dimensions on technology usage through mediators proposed by the quality-value-satisfaction chain and technology acceptance model. The results suggest stronger relationships for motivators than for inhibitors, but also that these TR dimensions exert influence through different mediators. Further, the moderator results suggest that the strength of TR-technology usage relationships depends on the technology type (hedonic/utilitarian), examined firm characteristics (voluntary/mandatory use; firm support), and country context (gross domestic product; human development). Finally, customer age, education, and experience are related to TR. These findings enhance managers' understanding of how TR influences technology usage.
\end{abstract}

Keywords Meta-analysis · Technology readiness · Technology acceptance $\cdot$ Quality-value-satisfaction chain $\cdot$ Structural equation modeling $\cdot$ Hierarchical linear meta-analysis

During the last decade, technological advances including mobile commerce, social media, and smartphone technology have impacted nearly every consumer's life. Despite increased diffusion of these technologies, marketing research still stresses that customers' use of technology is not a given (Claudy et al. 2015;

Mark Houston and John Hulland served as special issue editors for this article.

Electronic supplementary material The online version of this article (https://doi.org/10.1007/s11747-019-00680-8) contains supplementary material, which is available to authorized users.

Markus Blut

m.blut@aston.ac.uk

Cheng Wang

cheng.wang@xjtlu.edu.cn

1 Aston Business School, Aston University, Aston Triangle, Birmingham B4 7ET, UK

2 International Business School Suzhou, Xi'an Jiaotong-Liverpool University, 111 Ren Ai Road, Suzhou 215123, Jiangsu, China
Parasuraman and Colby 2015; Westjohn et al. 2009). Studies have frequently examined factors that potentially influence technology usage (Collier and Sherrell 2010; Dabholkar and Bagozzi 2002; Sääksjärvi and Samiee 2011). These factors relate to the technology, including ease of use and usefulness, and to the consumer, such as sociodemographics (Giebelhausen et al. 2014; Homburg et al. 2010; Meuter et al. 2005; Montoya-Weiss et al. 2003; Nysveen et al. 2005). Recently, scholars have increasingly considered the role of customer traits in explaining technology usage (Westjohn et al. 2009; Zhu et al. 2007), which gives marketers insights into which customers are most likely to use specific technologies. One trait variable that has received significant attention in recent research is technology readiness (TR) (Barrutia and Gilsanz 2013; Rojas-Méndez et al. 2017; Van Doorn et al. 2017). However, since the dimensionality of TR and its effect on technology usage is still not clear in the literature, a meta-analysis is needed.

Parasuraman (2000) defined TR as "people's propensity to embrace and use new technologies for accomplishing goals in home life and at work" (p. 308). It has been used to explain technology usage of external and internal customers (i.e., 
employees). Marketers use TR to assess the extent to which new technologies can be employed in customer-company interactions, the types of technologies to introduce, the pace of implementation, and the customer support required (Parasuraman 2000). TR is a trait-like individual difference variable that captures people's general attitude toward accepting new technologies. It is a frequent psychographic variable in decision-oriented research and for marketing managers in contexts where technology-based innovation is key. Some studies have found TR to be related to higher adoption rates of technologymediated services individuals use at home and work, including Internet banking, mobile technologies, social robots, selfcheckout terminals, remote services, online taxation systems, and cloud computing. Parasuraman and Colby (2015) reported that 127 researchers in 30 countries have used the TR index. ${ }^{1}$ While TR has been widely applied by marketing scholars and practitioners alike, it has been conceptualized from both complex multi-dimensional and simple unidimensional perspectives, which has caused confusion about its dimensionality and resulted in inconsistent and incompatible findings. Therefore, to consolidate the literature, a parsimonious but nuanced dimensionalization of the construct is much needed. Using data from 193 samples reported by 69,263 individuals, our study aims to advance understanding of the TR construct by reexamining its dimensionality, and investigating mediating mechanisms and moderating influences in the TR-technology usage relationship.

First, extant conceptualizations of the TR construct are unclear. Initially, it was proposed to comprise four separate dimensions: innovativeness, optimism, insecurity, and discomfort. Some studies have combined these dimensions to an overall composite measure, while ignoring the four dimensions' differential effects (Parasuraman and Colby 2015). Parasuraman and Colby $(2015$, p. 61) indicated that some "researchers seeking permission to use the scale were only interested in measuring overall TR." They explained that optimism and innovativeness represent "motivators," which contribute to TR, whereas insecurity and discomfort are "inhibitors," which lower an individual's TR. Thus, there is need for assessment of how to conceptualize the TR construct; either as four-dimensional, two-dimensional, or one-dimensional. Our findings suggest that TR is best conceptualized as a twodimensional construct comprising motivators (innovativeness, optimism) and inhibitors (insecurity, discomfort), thus offering marketing researchers and practitioners a parsimonious yet comprehensive way to measure consumers' TR level.

Second, the meta-study examines the impact of TR on technology usage. This relationship is of great interest and importance, because technology infusion is increasingly prominent in marketing activities, especially service encounters

\footnotetext{
${ }^{1}$ Based on the number of licenses given to scholars using the scale. Most of the 127 authors should be included in the current meta-study, which examines 163 articles.
}

(Giebelhausen et al. 2014; Van Doorn et al. 2017), and it is imperative that marketers understand which consumers are more ready to use technology. Existing findings on the TRtechnology usage relationship have frequently been inconsistent. While some studies have reported significant effects (Rahman et al. 2017), others have reported no effects at all (Chen et al. 2009). While it may be that the chosen construct conceptualization is responsible for the non-significant findings, it is also possible that TR is actually not significantly related to technology usage. Thus, there is a need to assess whether the consumers' TR is related to technology usage. Meta-analyses are recommended for such assessments since they have greater power compared to single studies, which often rely on small samples (Blut et al. 2016). Our results show that the direct impact of both motivators and inhibitors is either weak or nonsignificant, suggesting that marketers should probably not use TR as an immediate, direct predictor of technology usage.

Third, we consider the role of mediators between TR and technology usage. Our literature review indicates that the TR construct has been examined in the marketing and technology acceptance literatures. While some studies have considered mediators proposed by the quality-value-satisfaction (QVS) chain (Cronin et al. 2000), others have used mediators suggested by the technology acceptance model (TAM), such as usefulness of technology (Davis et al. 1989). Parasuraman and Colby (2015) encouraged scholars to integrate TR into larger nomological networks to better understand how TR influences technology usage. Our meta-analysis reveals that both motivators and inhibitors exert strong indirect influences, but through different mediators, thus offering marketers new insights into the processes how TR impacts technology usage.

Fourth, since the TR index has been applied in various contexts to explain technology usage, we assess the influences of contextual moderators. We focus particularly on actionable moderators that managers can control. Besides testing the influence of technology type (work/private use; hedonic/utilitarian) on the TR-technology usage relationship, we assess whether firm characteristics (voluntary/mandatory use; firm support) and country context (gross domestic product [GDP]; human development index [HDI]) are responsible for varying extant findings. We find that the effects of motivators and inhibitors are moderated by different technology, firm, and country factors. These findings provide insights into the generalizability of TR effects across contexts, and can guide marketers in decisions on when and how to offer technology-mediated services to customers.

\section{Literature review}

\section{Technology readiness construct}

According to Parasuraman (2000), TR is a trait-like variable that captures people's general attitude toward accepting new 
technologies. Based on the Metatheoretic Model of Motivation and Personality (3 M Model) (Mowen 2000), Westjohn et al. (2009) categorized TR as a situational trait that describes enduring dispositions to behave within a specific domain (i.e., technology-related behaviors). The $3 \mathrm{M}$ Model distinguishes between different types of traits according to stability. The most stable are higher-order elemental traits (e.g., the five-factor personality model; Mowen 2000), since these are determined by an individual's genetics and learning experiences as a child. In comparison, lower-order situational traits such as TR are less stable and are subject to change, because they are domain specific and might be influenced by an individual's situational environment and prior experiences. These trait characteristics distinguish TR from some related constructs.

The first related construct is technology anxiety, which is the fear and apprehension people feel when considering use of or actually using technological tools (Meuter et al. 2003). While both are individual characteristics of a person's technology predisposition, according to Meuter et al. (2003, p. 900) "TR is a relatively broad construct focusing on such issues as innovativeness and the tendency to be a technology pioneer. Technology anxiety specifically focuses on the user's state of mind regarding their ability and willingness to use technology-related tools." Meuter et al. (2003) explained that technology anxiety is related to, but distinct from, TR. However, they did not clarify the specific relationship between the constructs. While TR could be an antecedent of technology anxiety, technology acceptance studies have typically not assessed the constructs' interrelationship, and have often included only one of them. ${ }^{2}$ Second, TR should not be confused with "attitude," defined as an individual's positive or negative feelings (evaluative affect) about using a specific technology (Venkatesh et al. 2012). Although both are attitudinal variables (Parasuraman 2000), the former is an individual's general innate attitude (i.e., attitude toward technology in general), and the latter is a context-specific behavioral attitude (i.e., attitude toward using a specific technology; Wixom and Todd 2005). Third, TR differs from "self-efficacy" and "expertise," which capture beliefs in one's ability to use a technology. While readiness implies some level of ability, TR is a more generalized individual difference concept compared to the two specific technology-related ability beliefs. Finally, TR is distinct from "perceived risk," which refers to concerns about security, system failure, reliability, and other personal, psychological, or financial risks associated with using technology (Walker et al. 2002). TR captures both positive and negative views of technology in general, whereas perceived risk focuses only on the negative side of using a specific technology. ${ }^{3}$

\footnotetext{
${ }^{2}$ Compared to Blut et al. (2016), we observe that most TR effects are significant, as is technology anxiety. The reported effect sizes are also comparable $(\mathrm{r}=-.13)$. Some TR effects are even stronger than technology anxiety.

${ }^{3}$ Conceptually, TR is an antecedent to self-efficacy, risk, and attitude, because it is a technology-related personal trait, while the other constructs are specific beliefs about and attitudes toward a specific technology.
}

Dimensionality of the technology readiness construct

According to Parasuraman's (2000) initial conceptualization, TR has four dimensions (see Table 1): innovativeness and optimism, representing "motivators" contributing to TR, and discomfort and insecurity, which are "inhibitors" detracting from it. This multifaceted characteristic has caused inconsistencies in conceptualizations of TR, and it is unclear whether TR is best understood as a four-dimensional (innovativeness, optimism, insecurity, discomfort), two-dimensional (motivators, inhibitors), or one-dimensional (overall composite) construct. Many studies have treated TR as a four-dimensional construct and examined the individual effect of each dimension (Lam et al. 2008; Son and Han 2011). While this approach may more fully capture the TR construct and its effects, it is not without criticism. For example, the full instrument to measure the four TR dimensions is very long, making it inconvenient to use (Parasuraman and Colby 2015); additionally, the two motivator (inhibitor) dimensions have often been found to display similar effects empirically (Liljander et al. 2006), which raises the question of whether it is necessary or meaningful to treat them as distinct dimensions. Other studies have adopted a onedimensional conceptualization by combining the four dimensions into overall TR, ${ }^{4}$ or using one dimension to represent TR (Vize et al. 2013). Although methodologically convenient, this may hinder investigation of differential effects of the four TR dimensions and fail to reveal the complete role that different dimensions play in explaining technology usage. However, some studies have used a two-dimensional model to conceptualize TR regarding motivators and inhibitors (Jin 2013). This intermediate approach might provide a good compromise between the overly general but relatively simple one-dimensional model, and the more complete but complex four-dimensional one. Scholars have also debated whether broad personality traits are the most useful and parsimonious way to describe an individual's personality, or whether a greater variety of more narrowly defined dimensions is more suitable (Tett et al. 2003). The argument for a broad measure is that complex behaviors (e.g., technology use) require complex trait measures (i.e., composite TR), whereas specific measures (i.e., the four TR dimensions) do not dilute important variance in specific facets. Scholars have assessed how trait variables such as the five-factor personality model are best conceptualized (Tett et al. 2003); the TR literature would benefit from similar assessment.

\section{Consequences of technology readiness}

Some studies have found TR to be related to technology usage (Parasuraman and Colby 2015), which is arguably the most

\footnotetext{
${ }^{4}$ When calculating overall TR score, scholars have reverse-coded scores for discomfort and insecurity before calculating the average across the four dimensions.
} 
Table 1 Construct definitions and aliases

\begin{tabular}{|c|c|c|}
\hline Construct & Definition & Alias(es) \\
\hline \multicolumn{3}{|l|}{ Outcomes } \\
\hline Usage behavior & Actual system use in the context of technology acceptance (Davis et al. 1989) & Actual usage, adoption, continuance usage \\
\hline Usage intention & The strength of one's intention to use a technology (Davis et al. 1989) & Behavioral intention, continuance intention \\
\hline \multicolumn{3}{|l|}{ TAM-Mediators } \\
\hline Ease of use & $\begin{array}{l}\text { The degree to which a user would find the use of a technology to be } \\
\text { free from effort (Davis et al. 1989) }\end{array}$ & Complexity, effort expectancy \\
\hline Usefulness & $\begin{array}{l}\text { The subjective probability that using a technology would improve the } \\
\text { way a user could complete a given task (Davis et al. 1989) }\end{array}$ & Performance expectancy, relative advantage \\
\hline \multicolumn{3}{|l|}{ QVS-Mediators } \\
\hline Quality & $\begin{array}{l}\text { The degree to which an individual believes that the system performs his } \\
\text { or her tasks well (Venkatesh and Davis 2000) }\end{array}$ & Outcome quality, output quality, service quality \\
\hline Value & $\begin{array}{l}\text { An individual's cognitive tradeoff between the perceived benefits of the } \\
\text { technology and the cost for using it (Venkatesh et al. 2012) }\end{array}$ & Price value \\
\hline Satisfaction & An affective state that is the emotional reaction to technology experience (Spreng et al. 1996) & - \\
\hline \multicolumn{3}{|c|}{ Technology Readiness } \\
\hline Discomfort & $\begin{array}{l}\text { A perceived lack of control over technology and a feeling of being } \\
\text { overwhelmed by it (Parasuraman 2000) }\end{array}$ & - \\
\hline Innovativeness & A tendency to be a technology pioneer and thought leader (Parasuraman 2000) & $\begin{array}{l}\text { Personal innovativeness, consumer } \\
\text { innovativeness }\end{array}$ \\
\hline Insecurity & $\begin{array}{l}\text { Distrust of technology, stemming from skepticism about its ability to work } \\
\text { properly and concerns about its potential harmful consequences (Parasuraman 2000) }\end{array}$ & - \\
\hline Optimism & $\begin{array}{l}\text { A positive view of technology and a belief that it offers people increased control, } \\
\text { flexibility, and efficiency in their lives (Parasuraman 2000) }\end{array}$ & - \\
\hline Motivators & $\begin{array}{l}\text { The positive dimension of TR that comprises two traits-innovativeness and } \\
\text { optimism (i.e., the drivers/enablers that improve an individual's TR) (Parasuraman 2000) }\end{array}$ & - \\
\hline Inhibitors & $\begin{array}{l}\text { The negative dimension of TR that comprises two traits-discomfort and insecurity } \\
\text { (i.e., the detractors that lower an individual's TR) (Parasuraman 2000) }\end{array}$ & - \\
\hline $\begin{array}{l}\text { TR } \\
\text { (Composite) }\end{array}$ & $\begin{array}{l}\text { A composite measure of people's propensity to embrace and use new technologies to } \\
\text { accomplish goals in home life and at work (Parasuraman 2000) }\end{array}$ & - \\
\hline \multicolumn{3}{|c|}{ 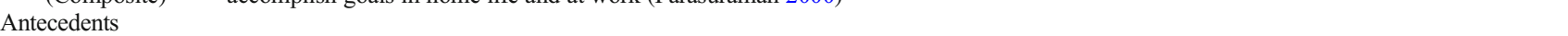 } \\
\hline Age & An individual's age & - \\
\hline Education & An individual's educational attainment level & _- \\
\hline Experience & $\begin{array}{l}\text { The number of technology-related experiences that have been accumulated by an } \\
\text { individual (Alba and Hutchinson 1987) }\end{array}$ & Familiarity, past usage \\
\hline
\end{tabular}

important consequence of TR. To understand this relationship, researchers have investigated the mechanisms/processes through which TR influences technology usage within two primary research streams: the QVS chain, grounded in marketing literature (Cronin et al. 2000), and the TAM, from information systems (IS) literature (Davis et al. 1989). The QVS literature argues that people with higher TR generally evaluate a technology more highly regarding quality, value, and satisfaction, which then increases their usage intention and/or actual use (Parasuraman and Grewal 2000). That is, quality, value, satisfaction, or a combination thereof mediates TR's influence on technology usage. Conversely, the TAM literature typically suggests that the higher an individual's TR, the more useful and easier to use they find a technology, and therefore the more likely they are to use it (Blut et al. 2016). Thus, usefulness and ease of use mediate the TR-technology usage relationship. Comparing the two research streams reveals similarities and differences that motivate this study's conceptual development. Both seem interested less in the direct effect and more in the indirect effect of TR on technology usage. This corresponds with the broad attitude-behavior literature, which has posited that general attitudes (TR) are weak predictors of behaviors (technology usage; Ajzen and
Fishbein 2005). It is also consistent with the critique that the trait-behavior model inadequately represents innovation adoption behavior. According to Midgley and Dowling (1978, p. 240), "[w]ithout a model of the processes intervening between trait and behavior we are in no position to ascribe any meaning to empirical correlations. Such a model is a vital stepping stone." Thus, it is necessary to explore mediators to build a meaningful conceptual bridge. However, the research streams differ in the types of mediators used. Regarding the QVS approach, while quality, value, and satisfaction are proposed to capture an individual's comprehensive and overall evaluation of a technology, they offer little insight into what specific technology perceptions influence usage and are influenced by TR. The TAM, conversely, focuses on two specific, actionable mediators (usefulness and ease of use), sacrificing a holistic view and other relevant technology beliefs.

\section{Antecedents of technology readiness}

Research on antecedents of TR is limited (Parasuraman and Colby 2015), because TR is considered a stable, individuallevel, trait-like characteristic and, therefore, is often included as an endogenous factor in technology acceptance studies. 
Prior research has mainly focused on two categories of factors that might impact or correlate with TR: demographics and past experience. Regarding demographics, Dutot (2014) found age to be negatively associated with TR, meaning that younger and better-educated people generally use new technologies more readily. However, these effects are sometimes nonsignificant (Gilly et al. 2012), perhaps because during the last 20 years all ages have become more familiar with technology. Other studies have focused on how experience influences TR, suggesting that the greater people's technology-related experience, the higher their TR. That is, experience is positively related to TR, especially its innovativeness dimension (Maier 2016). Because findings in this area are limited and inconclusive, we suggest that synthesizing prior results may consolidate understanding of the antecedents of TR.

\section{Moderators in technology readiness research}

Previous TR research has rarely examined moderators. For example, Hur et al. (2017) revealed generational differences in TR effects by comparing millennial and mature consumers. Massey et al. (2013) found that people's prior Web experience attenuates the influence of TR on a website's perceived usability. Regarding situational moderators, Lam et al. (2008) showed that the negative effect of one TR dimension, insecurity about Internet use, is stronger in high-risk usage situations. Theotokis et al. (2008) found that in technology-based services, the level of customer-technology interaction strengthens the effect of TR on customers' attitude toward the service. However, since TR has been studied for several hundred thousand customers using various technologies provided by firms around the world (Parasuraman and Colby 2015), a rigorous, large-scale, cross-context study is warranted to assess the generalizability of TR effects across technologies, firms, and countries.

\section{Conceptual model and hypotheses}

Figure 1 shows the meta-analytic framework in which TR is the focal construct. First, our conceptualization of TR is twodimensional, since this compromises between model parsimony and accuracy in describing the construct's facets. Second, we propose a direct effect of TR on technology usage. The hypotheses suggest that customers who are more technology ready are more likely to use a specific technology, as most studies have proposed a positive relationship between TR and technology usage. Third, we incorporate mediators for TR effects that are theoretically grounded in the TAM and QVS literatures. While the TR dimensions refer to an individual's view toward technology in general, the mediator variables refer to an individual's beliefs about a specific technology. Fourth, drawing on trait-formation theory, the framework includes demographics and experience as antecedents of TR. Finally, it focuses on contextual moderators characterizing the technology, firm, and country context.

The model differs compared to a recent meta-analysis that also considered TR. Blut et al. (2016) explained technology usage by investigating all major determinants and their relative importance, whereas we focus on TR as the only

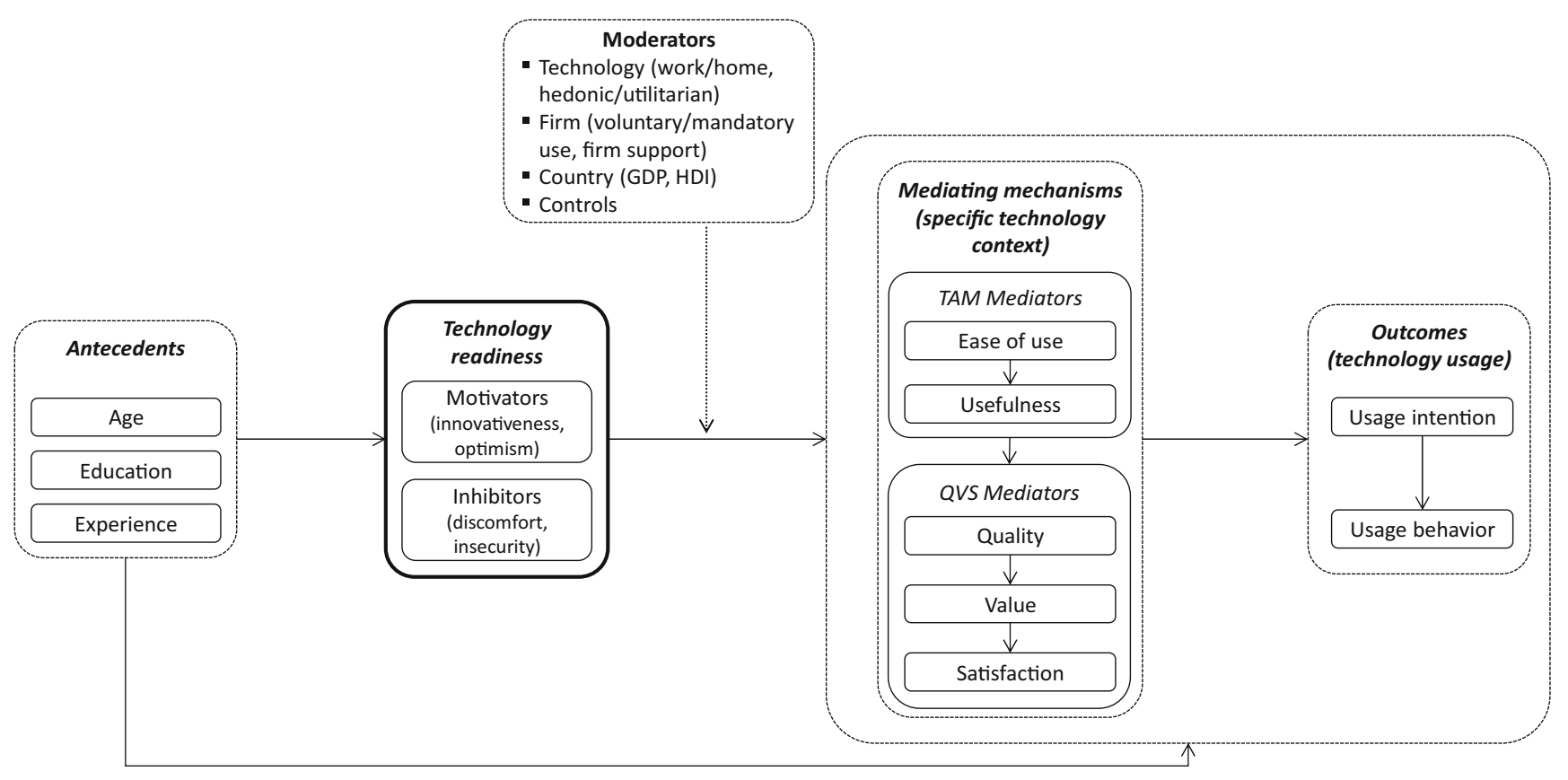

Fig. 1 Meta-analytic framework 
determinant to enhance understanding of the construct itself and its impact on technology usage. Blut et al. (2016) did not test alternative TR conceptualizations, or moderators for the TR-technology usage relationship. Thus, our study theorizes differential moderating effects for different TR dimensions. Further, while both studies examine mediators, we go beyond TAM and also include QVS variables as alternative mediating mechanisms. Further, we include more effect sizes from a wider range of technologies, whereas Blut et al. (2016) examined self-service technologies; for example, they examined only two effect sizes for TR technology usage $(N=1,562)$, whereas we examine 21 effect sizes for motivators $(N=$ $9,043)$ and 12 for inhibitors $(N=5,233)$. Contrary to Blut et al. (2016), we also examine antecedents of TR. While they only reported averaged effect sizes using descriptive statistics, we test the conceptual model in a comprehensive structural equation model (SEM).

We develop TR-related hypotheses at the two-dimensional level. We do not hypothesize relationships between and among mediators and outcomes, nor the effects of antecedents on mediators/outcomes, because these are already established in the TAM and QVS literatures. For example, we consider the effects of ease of use on usefulness and usefulness on perceived value (Davis et al. 1989). Construct definitions appear in Table 1.

\section{Direct effects of technology readiness on technology usage}

Motivators (innovativeness, optimism) Motivators are the positive dimension of TR that comprises two traitsinnovativeness and optimism. They are the drivers/enablers that improve an individual's TR. Innovativeness refers to a tendency to be a technology pioneer and thought leader (Parasuraman 2000). Consumer innovativeness research has found that this intrinsic individual characteristic highly correlates with consumers' novelty-seeking and creativity behaviors, such as adoption of new products (Hirschman 1980). Therefore, regarding technology adoption, we expect that individuals with a high degree of innate innovativeness (i.e., openness to new things) show inherent interest in trying new technologies, and become innovators or early adopters (Rogers 1995). Optimism refers to a positive view of technology and a belief that it offers increased control, flexibility, and efficiency in people's lives (Parasuraman 2000). As optimists feel favorably toward technology in general, they tend to see more benefits (e.g., convenience) in specific technologies and worry less about negatives (Son and Han 2011). For example, Hwang and Good (2014) found a strong positive relationship between optimism and adoption intention regarding intelligent-sensor-based services, both when consumers received positive and negative information about the technology. Thus, we expect TR motivators to be highly motivated to adopt technologies in their lives and at work. Hence,

$\mathrm{H1}$ : Motivators are positively related to (a) usage intention and (b) usage behavior.

Inhibitors (discomfort, insecurity) Inhibitors are the negative dimension of TR that comprises two traits - discomfort and insecurity. They are the detractors that lower an individual's TR. Parasuraman (2000) defined discomfort as a perceived lack of control over technology and a feeling of being overwhelmed by it. Drawing on perceived-control research, we expect a negative relationship with technology usage. The theory of planned behavior explicitly includes perceived behavioral control as a direct determinant of both behavioral intention and actual behavior (Ajzen and Fishbein 2005). Moreover, studies have found that consumers' control beliefs positively affect their adoption of self-service technologies (Dabholkar 1996). Thus, discomfort, as an individual's general feeling of lack of control, should have a negative effect. People with a high level of discomfort find using a technology unpleasant and overwhelming, and thus try to avoid it. Insecurity refers to distrust of technology, stemming from skepticism about its ability to work properly and concerns about potential harmful consequences (Parasuraman 2000). It combines general safety concerns, worries about negative outcomes, and a need for assurance. If individuals are naturally distrustful of and skeptical about technology, they tend to expect risks rather than benefits in any technology, and consequently avoid it. As trait theory suggests, we expect a negative relationship between insecurity trait and technology usage. IS research has indicated that trust is important in determining technology adoption behavior (Venkatesh et al. 2012). Hence, we assume the TR inhibitors to be negatively related to technology use. Thus,

H2: Inhibitors are negatively related to (a) usage intention and (b) usage behavior.

\section{Indirect effects of technology readiness via the TAM mediators}

Ease of use Davis et al. (1989) defined ease of use as the degree to which a user finds use of a specific technology to be free from effort. The TAM posits that a technology perceived as easier to use is more likely to be adopted. This is because a complicated, confusing technology is more difficult to understand and operate, and may make the benefits less apparent (Meuter et al. 2005), thus decreasing consumers' ability and willingness to use it. We expect that ease of use mediates the effects of the different TR dimensions. First, we assume a positive relationship with TR motivators. Innovative people seek to learn about new technologies, and thus tend to 
better understand how a technology works, leading to perceptions of needing less effort in use. Additionally, optimists generally hold positive attitudes toward technology, making them willing to spend more time/effort on it. Therefore, for the same level of actual effort invested, perceptions of effort are lower for more optimistic, compared to less optimistic, consumers (Venkatesh 2000). Second, we propose a negative relationship with TR inhibitors. Due to perceived lack of control, people high in discomfort often have low confidence in using a technology, therefore finding its use more difficult. This is because confidence in one's ability forms a basis for individuals' judgment about how easy a technology is to use (Venkatesh 2000). Skeptical people, due to their inherent distrust of technology, are less interested in learning how to use a technology, and more likely to find its use difficult. Thus,

H3: Ease of use is (a) positively related to motivators, and (b) negatively related to inhibitors.

Usefulness Usefulness refers to the subjective probability that using a technology will improve the way a user completes a given task (Davis et al. 1989). According to the TAM, for a technology to be accepted people must be convinced that using it offers benefits, such as time/cost savings and improved task performance. Like ease of use, researchers have proposed usefulness as a key mediator in explaining consumer acceptance of technology (Venkatesh and Davis 2000); therefore, we expect it to mediate TR and technology usage. First, motivators are positively related to usefulness (Rahman et al. 2017). Innovative people naturally enjoy interacting with technologies. Thus, for the same actual benefits obtained, perceptions of usefulness are higher for more innovative consumers. These people are also more likely to find additional benefits in a technology through experimentation and exploration. Moreover, compared with less optimistic people, optimists tend to focus on positive aspects of a technology and see more benefits in it, leading to higher perceived usefulness. Second, inhibitors are negatively related to usefulness (Jin 2013). People high in discomfort perceive a technology as less useful because they are less confident in their ability to control it, and thus less likely to find and enjoy benefits during usage. Additionally, skeptical people perceive a technology as less useful because they are generally more concerned about risks in usage and tend to doubt benefits from using it. Therefore,

H4: Usefulness is (a) positively related to motivators, and (b) negatively related to inhibitors.

\section{Indirect effects of technology readiness via the QVS mediators}

Quality In our context, quality can be defined as the degree to which individuals believe that the technology performs their tasks well (Venkatesh and Davis 2000). Thus, higher quality means better outcomes from using a technology. It differs from "usefulness," as quality is an overall evaluation focusing on results after usage and usefulness is a specific belief focusing on benefits of usage itself. As a central concept in marketing, quality is a key driver of consumer behaviors such as purchase intention (Zeithaml et al. 2002). Specifically, studies have found that service quality influences consumers' acceptance of self-service technologies (Dabholkar 1996). This study follows Zeithaml et al.'s (2002) proposition that TR influences technology usage through quality perception, and hypothesizes effects of TR on quality. First, motivators are positively related to quality. Innovative people are generally more able to cope with and make the most of a technology, and therefore more likely to achieve better results from using it. Furthermore, we suggest that optimists generally emphasize positives over negatives in evaluating the outcome of using a technology, leading to a higher quality perception (e.g., Liljander et al. 2006). Second, inhibitors are negatively related to quality. People high in discomfort find using a technology uncontrollable and overwhelming, resulting in lower quality perceptions regardless of actual outcome. Also, skeptical people generally evaluate the outcome of using a technology more negatively due to their inherent belief that some harmful consequences must be involved. This lower perceived quality is then consistent with their distrust of technology. Thus,

H5: Quality is (a) positively related to motivators, and (b) negatively related to inhibitors.

Value Value refers to an individual's cognitive tradeoff between the technology's perceived benefits and the cost of using it (Venkatesh et al. 2012). The marketing literature has broadly viewed value as "consumers' overall assessment of the utility of a product based on perceptions of what is received and what is given" (Zeithaml 1988, p. 14), and has widely agreed that value perception is a key determinant of consumers' intentions and behavior (Cronin et al. 2000). For example, marketing research has found that perceived value is positively related to consumers' intentions to use self-service technologies (Collier and Sherrell 2010). Technology acceptance literature has explicitly included price value as a determinant of behavioral intention (Venkatesh et al. 2012). ${ }^{5}$ Yieh et al. (2012) found that all TR dimensions are significantly related to customer perceived value in a technology. Hence, we expect that value mediates the effects of TR on technology usage and that in general the higher the TR, the higher the perceived value. First, we propose a positive relationship with motivators. Innovativeness is positively related to value,

\footnotetext{
${ }^{5}$ Most studies on technology usage have treated usefulness and value as two separate, unrelated constructs, as proposed by unified theory of acceptance and use of technology (Venkatesh et al. 2012).
} 
because innovators are keen to experiment with technology and such exploration enables them to achieve more value by using it (Barrutia and Gilsanz 2013). Moreover, optimism is positively related to value, because optimists generally focus on the positive rather than negative side of a technology, leading to a higher value evaluation toward it. Second, we propose a negative relationship with inhibitors (Yieh et al. 2012). Discomfort is negatively related to value, because people high in discomfort are more likely to experience frustration and anxiety with a technology (i.e., high non-monetary cost), resulting in lower perceived value. Moreover, insecurity is negatively related to value, because skeptical people generally expect risks rather than benefits in using a technology, resulting in lower value perceptions. Thus,

H6: Value is (a) positively related to motivators, and (b) negatively related to inhibitors.

Satisfaction Spreng et al. (1996) defined satisfaction as an affective state that is an emotional reaction to a technology experience. As the last construct in the QVS chain, satisfaction has been extensively investigated as a direct determinant of marketing outcomes, such as customer loyalty (Szymanski and Henard 2001). Technology acceptance studies have also included it as an individual's overall affective evaluation that directly influences technology usage (Wixom and Todd 2005). Hence, we expect satisfaction to be another key mediator between TR and technology usage, and anticipate TR to positively affect customer satisfaction. First, TR motivators are assumed to be positively related to satisfaction. Innovative people are more likely to gain greater satisfaction with a technology because they are naturally enthusiastic about technology and find the technology experience more stimulating and pleasant. Given their favorable disposition toward technology, optimists are more easily satisfied because they tend to focus on the positives of technology (Liljander et al. 2006). Second, TR inhibitors are negatively related to satisfaction. People high in discomfort are more likely to feel overwhelmed when using a technology, which makes the technology experience less satisfactory. Skeptical people are less likely to gain satisfaction from a technology because they mistrust it and have security concerns (Vize et al. 2013). Thus,

H7: Satisfaction is (a) positively related to motivators, and (b) negatively related to inhibitors.

\section{Antecedents of technology readiness}

Age Trait-formation theories emphasize that personality traits are formed partially due to an individual's ability to learn and prior learning experiences (Anastasi 1983). Because TR dimensions are situational traits, we expect age to be related to one's TR level. First, age is negatively related to motivators
(Dutot 2014). Older people are generally considered less innovative because they are more reluctant to change. They are typically less optimistic because they are less able to see the benefits of using new technologies due to reduced cognitive learning capabilities (Rojas-Méndez et al. 2017). Second, age is positively related to inhibitors. Older people are more likely to feel uncomfortable about using new technologies, again due to their reduced cognitive capabilities. They generally tend to be skeptical about new things given their richer life experience; thus, they are more likely to feel insecure about new technologies. Hence,

H8: Age is (a) negatively related to motivators, and (b) positively related to inhibitors.

Education Referring to trait-formation theory, we expect education to be related to an individual's TR (Anastasi 1983). First, education is positively related to motivators. Highly educated people are more innovative because they have more sophisticated cognitive structures that enable learning in new environments (Rojas-Méndez et al. 2017). This makes them more ready and likely to be among the first to try new technologies. Because education increases one's ability to learn and adapt in new environments, it stimulates a more optimistic view of new technologies. Second, education is negatively related to inhibitors. Highly educated people, due to their sophisticated cognitive learning capabilities, tend to be more confident in their ability to control technology, and therefore less likely to feel uncomfortable or overwhelmed when using technology. Since education increases people's learning abilities in new situations, it helps to reduce their reservations, as they are able to understand new technologies better (RojasMéndez et al. 2017). Therefore,

H9: Education is (a) positively related to motivators, and (b) negatively related to inhibitors.

Experience We define experience as the number of technology-related experiences an individual has accumulated (Alba and Hutchinson 1987). We expect past experience to positively influence an individual's TR (Vize et al. 2013). First, experience is positively related to motivators. Research has suggested that past experience with technology increases an individual's propensity to adopt further technologies (Vize et al. 2013). Thus, experienced people are likely to be more innovative by habit. Furthermore, experience is related to optimism. With more experience, people are technologically savvier and, hence, more likely to understand the benefits of using technology, leading to a more positive view of technology in general. Second, we assume a negative relationship with inhibitors, positing that experience helps ease the discomfort because of greater familiarity with technology in general. Finally, similar to discomfort, we expect experience to 
reduce the feeling of insecurity regarding technology through experience-based trust. Thus, experience is negatively related to inhibitors. Therefore,

H10: Experience is (a) positively related to motivators, and (b) negatively related to inhibitors.

\section{Moderating effects of technology types}

Moderating role of work versus home technologies When developing the TR index, Parasuraman (2000, p. 318) explained that the scale can be used not only for external customers, but also "to assess the technology readiness of internal customers (i.e., employees)." We therefore differentiate between work technologies used by employees as part of their jobs in an organizational context, and home technologies used by consumers for private reasons in non-organizational settings (Venkatesh et al. 2012). ${ }^{6}$ We consider this moderator because it is defined quite broadly, covering different use contexts examined in prior research. Moreover, the technology acceptance literature has acknowledged potential differences between both use contexts (Venkatesh et al. 2012). The unified theory of acceptance and use of technology was developed for organizational contexts and extended to consumer settings (Venkatesh et al. 2012). It has been argued that theories focusing on a specific context, rather than general theories, are important for enhancing understanding of a focal phenomenon. Venkatesh et al. (2012) further justified this extension when tailoring it to consumer settings, arguing that consumers are more likely to engage in technology usage because of factors related to themselves, as opposed to the organization. In organizational contexts, technology use is often mandated by the firm regardless of how employees perceive that technology. Both TR motivators and inhibitors relate to the customer's own views on technology; thus, we assume these two TR dimensions to gain importance in consumer settings. While customers scoring high in TR motivators are more likely to enjoy technology use, customers scoring high in TR inhibitors are less likely. These technology beliefs are more likely to influence perceptions and use of technology in consumer contexts. Hence,

H11: The effects of (a) motivators and (b) inhibitors on technology perceptions ${ }^{7}$ and usage are stronger for technologies used in the home than in the work context.

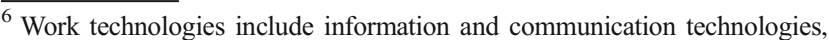
instant messaging, cloud computing, data mining technology, Internet banking, and wireless technology. Home technologies include self-service technologies and mobile payment, smart virtual closets, social media, and electronic book readers.

${ }^{7}$ To improve the readability of the moderator hypotheses and better relate them to theory, we use technology "perceptions" to refer to the five mediator variables and "usage" to the two outcome variables.
}

Moderating role of hedonic versus utilitarian technologies Marketing literature has long compared hedonic versus utilitarian consumption motives (Babin et al. 1994), and firms providing hedonic versus utilitarian value to customers (Sheth et al. 1991). The technology acceptance literature also differentiates between hedonic and utilitarian technologies (e.g., van der Heijden 2004). A recent meta-study assessed several technology classifications, finding that most differences occur when comparing hedonic with utilitarian technologies (Blut et al. 2016). We therefore classify technologies depending on whether they provide hedonic (e.g., augmented reality fashion application) or utilitarian (e.g., Internet banking) services. While hedonic technologies are pleasure-oriented, utilitarian technologies are productivity-oriented (Massey et al. 2013). We expect that the TR motivators have a stronger influence on technology perception and use for hedonic technologies, whereas TR inhibitors display a stronger effect for utilitarian technologies. When a specific technology provides mainly hedonic benefits, consumers are more likely to use it if they appreciate these benefits. Parasuraman (2000) stressed, regarding TR motivators, that customers high in innovativeness receive pleasure from using technology because they enjoy the challenge of understanding high-tech gadgets and appreciate keeping up with technological developments. Similarly, he argued that people high in optimism find new technologies mentally stimulating, and learning about technology itself rewarding. Customers receive pleasure from technology independent of instrumental benefits. For utilitarian technologies, we expect TR inhibitors to show a stronger influence. Customers high in discomfort believe that technology is too complicated for use by ordinary people (Massey et al. 2013). Similarly, customers high in insecurity display general doubts that technology will work properly. Because these beliefs refer to the productivity of technology, they are more relevant when assessing utilitarian technologies. Thus,

H12: The effect of (a) motivators on technology perceptions and usage is stronger for hedonic technologies, whereas the effect of (b) inhibitors is stronger for utilitarian technologies.

\section{Moderating effects of firm characteristics}

Moderating role of voluntariness of technology use Parasuraman (2000) developed the TR index and tested its effects for various technologies, but like later scholars, did not consider that technology use is sometimes voluntary and sometimes mandatory. This is surprising since established acceptance theories consider voluntariness a key moderator of the relationship between technology beliefs and technology usage (Venkatesh et al. 2012). Voluntariness refers to the extent of free will involved in technology use (Wu and Lederer 2009). Voluntary actions differ from non-voluntary 
(mandatory) actions. Often, service firms mandate use of a specific technology without allowing customers to receive the service via other means. For example, many service firms are closing ticket counters and reducing the number of service staff; thus, customers must use self-service technologies such as ticket machines instead. While voluntary actions are internally determined by individuals, non-voluntary actions are coerced from outside (Wu and Lederer 2009). If technology use is voluntary, intention to use and actual usage reflect the customer's perceptions and beliefs regarding the technology, whereas customers in non-voluntary settings comply with firm policies (Hartwick and Barki 1994). Individuals realize in these contexts that their own beliefs are less relevant. Similarly, the customer's general technology beliefs are proposed to be more relevant in voluntary settings. In this context, the TR motivators/inhibitors are more likely to determine technology perception and use. Wu and Leder (2009) referred to the theory of reasoned action, arguing that an individual's beliefs influence behavioral intention and usage more strongly in voluntary-use settings. They suggested that voluntary behavior is mainly the result of the individual's favorable attitude and salient beliefs (Ajzen and Fishbein 2005). Therefore,

H13: The effects of (a) motivators and (b) inhibitors on technology perceptions and usage are stronger for voluntary than for mandatory technologies.

Moderating role of provided firm support Parasuraman (2000) suggested that firms should use the TR index to identify which customers are most likely to experience problems with technology-based systems and require support. Surprisingly, few studies have tested whether and how provided support impacts the effects of TR. Service firms frequently support customers when using technology for service provision (e.g., by providing online tutorials). While the service literature has usually assumed that support helps individuals who experience problems (Parasuraman 2000), other literature streams have argued that firm support is ambivalent in nature (Stewart et al. 1996). We therefore propose two competing hypotheses for firm support. First, according to the need-for-support perspective, low-TR customers - those low in motivators and high in inhibitors - are more likely to benefit from provided support, while high-TR customers can use technology independent of provided support (Stewart et al. 1996). Thus, there is a negative interaction effect between provided support and TR on technology perception and use. Customers who are high in TR motivators and low in inhibitors benefit less from firm support compared to customers who are low in TR motivators and high in inhibitors. Second, the opposite interaction effect is proposed by the classical theory of performance, which is the multiplicative function of ability and motivation (Stewart et al. 1996). This perspective suggests that high-TR customers display greater motivation to use technology and benefit more from support. Thus,
H14: The effect of (a) motivators on technology perceptions and usage is stronger when receiving firm support, whereas the effect of (b) inhibitors is weaker.

H15: The effect of (a) motivators on technology perceptions and usage is weaker when receiving firm support, whereas the effect of (b) inhibitors is stronger.

\section{Moderating effects of country characteristics}

Moderating role of gross domestic product Parasuraman and Colby (2015) called for more studies assessing the TR index in different country settings, since it is unclear whether the measurement works equally across countries. According to Kumar et al. (2018), the acceptance of any new technology, product, or service depends on macro- and micro-level characteristics. Thus, various meta-analyses have considered the influence of country characteristics on customer behavior (e.g., Auer and Papies 2019; Carrillat et al. 2018; Eisend 2010; Pick and Eisend 2014, 2016). These studies suggested that country differences may cause substantial variance in effect sizes. Without considering country differences, we implicitly assume that our theory is generalizable across countries (Burgess and Steenkamp 2006). We therefore consider the moderating influence of economic country variables, because economic differences (e.g., income level) are known to influence customer behavior in various countries (Pick and Eisend 2016). More specifically, the international marketing literature has discussed GDP per capita to be related to customers' purchasing power and preferences (Berry et al. 2010). Customers in low-GDP countries have less disposable income, making them more vulnerable when making wrong purchase decisions. They are often concerned about satisfying basic needs with limited financial resources (Berry et al. 2010). Therefore, their desire to avoid potential negative consequences associated with technology usage drives their decision-making regarding technology usage more strongly compared to technology's ability to satisfy other, psychological and self-fulfillment, needs. TR inhibitors (discomfort, insecurity) refer to general views about negative consequences of technology. Thus, customers in low-GDP countries consider these beliefs more strongly in their decision-making. Contrarily, available financial resources pose fewer constraints on customers in high-GDP countries, who typically try to satisfy other psychological and self-fulfillment needs once basic needs have been met (Maslow 1954). The TR motivators display stronger effects on technology perceptions and usage as GDP increases, because technology allows customers to satisfy these needs. It is more important to customers in these countries that technology improves various aspects of life (optimism) and creates an image of their being technology pioneers and thought leaders (innovativeness). Thus, 
H16 The effect of (a) motivators on technology perceptions and usage is stronger in high-GDP countries, whereas the effect of (b) inhibitors is stronger in low-GDP countries.

Moderating role of human development The HDI is a widely used measure of a country's development (United Nations 2018), and one of the most influential country classifications (Burgess and Steenkamp 2006). It considers major country achievements, including healthy life, knowledge, and standard of living. Countries with low or medium human development are considered to be emerging, whereas high human development countries are considered to be developed. Sheth (2011, p. 166) explained that "emerging markets are radically different from the traditional industrialized capitalist society, and they will require us to rethink the core assumptions of marketing." Arcelus et al. (2005) demonstrated a strong nexus between a country's human development and its technology achievement. For example, healthcare providers in developed countries use mobile devices, healthcare apps, and other technologies to improve their provision of services. Kumar et al. (2018) examined the use of mobile payment technology in emerging markets, finding that technology perception in these markets differs from developed markets. We propose that customers in developed countries are more sensitive regarding the disadvantages of technology. Ayyagari et al. (2011, p. 831) argued that "[w]ith the proliferation and ubiquity of information and communication technologies (ICTs), it is becoming imperative for individuals to constantly engage with the technology." Johnson et al. (2008, p. 416) explained that "the spread of the Internet and wireless telecommunications has increased convenience and efficiency by making individuals continuously available but has also increased technological enslavement indicated by continuous partial attention and multitasking of communication with other activities." The literature has even coined the term "technostress" for this development; this is "a modern disease caused by one's inability to cope or deal with ICTs in a healthy manner" (Ayyagari et al. 2011, p. 832). Thus, developed countries have increasing awareness of what technologies can do to users. Thus, TR inhibitors-discomfort and insecuritydisplay stronger relationships with technology perceptions and usage in developed countries. Contrarily, customers with less technology access are less aware about its disadvantages, and consider its advantages (TR motivators) more strongly in decision-making. According to Mick and Fournier (1998), customers become increasingly aware about technology's disadvantages the more they have to deal with it. Thus,

H17 The effect of (a) motivators on technology perceptions and usage is stronger in low-HDI countries, whereas the effect of (b) inhibitors is stronger in high-HDI countries.

\section{Controls}

We include study year as a control variable because counterintuitive findings are more likely to be published in initial, rather than later, studies (Hunter and Schmidt 2004). ${ }^{8}$ Further, we control for the influence of student versus nonstudent samples; due to their homogeneity, student samples may produce stronger effect sizes, leading to lower error variance in measurement (Peterson 2001). We also consider quality of publication outlet, since high-quality journals have more rigid mechanisms to ensure correctness of analyses (Hunter and Schmidt 2004). We include publication status because significant effects are more likely than non-significant effects to be published (Hunter and Schmidt 2004). The technology acceptance literature has been unclear on how to incorporate customers' previous experience into models. While some studies have considered it an antecedent of technology usage, others have considered it a moderator (Venkatesh et al. 2012). We derive a main effect, as explained in H10. To assess the alternative moderating effect we also include experience among the moderating variables, though we do not derive a hypothesis therefrom. Finally, we control for cultural differences. Uncertainty avoidance in particular has been proven an important moderator in the technology acceptance literature (Srite and Karahanna 2006).

\section{Method}

\section{Literature search, selection criteria, and coding}

We searched for empirical studies testing TR, using several search strategies. To identify relevant studies, we individually examined all studies that cited the initial TR study from Parasuraman (2000). We also searched online repositories, including EBSCO (Business Source Premier), ABI/ INFORM, and dissertation databases (Proquest). We used Google Scholar to identify further studies. Keywords used included "technology readiness (index)," "motivator," "inhibitor," "innovativeness," "optimism," "insecurity," and "discomfort." Two related constructs were found when searching with "innovativeness": "consumer innovativeness" in the marketing literature (Goldsmith and Hofacker 1991) and "personal innovativeness" in the IS literature (Agarwal and Prasad 1998). Both are individual difference variables, and are often used interchangeably with TR's innovativeness (Barrutia and Gilsanz 2013). Therefore, we included these two constructs as the innovativeness dimension of TR. We used several

\footnotetext{
${ }^{8}$ We calculated additional models with further controls, and assessed the influence of service type (people-processing services, intangibility of services), technology type (simple technology, risk level of usage), and country characteristics (innovativeness, rule of law). Most of these control variables are non-significant.
} 
inclusion criteria for the meta-analysis. Studies had to: (1) be empirical, excluding qualitative and overview studies; (2) report information needed to calculate effect sizes and information on sample size; and (3) measure TR, either as a composite measure or decomposed into the two or four dimensions. Based thereon, the final dataset included 2,752 effect sizes extracted from 193 independent samples reported in 163 articles by 69,263 individuals. Because TR has been used to explain technology usage of both external and internal customers (i.e., employees), 45 of the 193 samples in the metastudy examined employees. Around $16 \%$ of the collected studies were not published in a journal. We collected studies from marketing and computer science that used the TR measurement (Web Appendix A).

We developed a coding scheme, which two expert coders used to systematically extract the study information. Since the effect size of this study is the correlation coefficient ( $r$ ), the coders tried to extract this information from the studies. If this information was unavailable, they coded information that they could use to calculate the correlation coefficients (e.g., standardized regression coefficients, t-values). For example, standardized beta coefficients were converted using Peterson and Brown's (2005) formula. The coders used the construct definitions in Table 1 to classify variables, and extracted information on sample size and reliability of the measurement employed. Finally, they coded the moderators of this study, including the type of technology (work/private, hedonic/utilitarian), firm characteristics (voluntariness/mandatory use, firm support), and country where the study was conducted. ${ }^{9}$ Country information was used to match the meta-data with secondary data about the country's GDP (International Monetary Fund 2017) and HDI (United Nations 2018). Control variables were also coded. Table 2 outlines the operationalization of various moderators. The coders displayed high consistency in their coding (97\% agreement).

\section{Effect size and effect size integration}

We use correlation coefficients to represent effect size, since the collected studies report this most often. We employ procedures suggested by Hunter and Schmidt

\footnotetext{
${ }^{9}$ The dataset includes TR samples from 35 countries: Australia, Austria, Bangladesh, Belgium, Brazil, Canada, Chile, China, Finland, France, Germany, Greece, India, Indonesia, Ireland, Italy, Malawi, Malaysia, Mexico, Netherlands, Norway, Pakistan, Singapore, South Africa, South Korea, Spain, Sweden, Taiwan, Thailand, Turkey, United Arab Emirates, United Kingdom, United States, and Yemen.

${ }^{10}$ For most relationships examined, we collected at least two effect sizes (66 of $70 \mathrm{TR}$ relationships). Meta-studies examining a larger number of variables have frequently reported just one effect size for single relationships (e.g., Palmatier et al. 2006; Verma et al. 2016).
}

(2004), which comprise a random-effects approach to meta-analysis. ${ }^{10}$ We first corrected the effect sizes for measurement error by dividing each correlation by the square root of the product of the reliabilities of the independent and dependent variables. When reliability information was unavailable, we substituted it with the average reliability of the respective construct. We then averaged the effect sizes when independent samples reported multiple correlations for a specific relationship; this approach ensures that samples reporting the same relationship numerous times do not receive disproportionate weight in analyses (Hunter and Schmidt 2004). We then corrected the effect sizes for sampling error by averaging them using sample-size weights (N - 3; Hunter and Schmidt 2004). We calculated the standard deviations and confidence intervals for each examined relationship, and calculated credibility intervals, which display the distribution of effect sizes. A large credibility interval suggests variation in effect sizes and the need for moderator analysis to account for unexplained variance. We also assessed the need to study moderators by calculating the Q-statistic test of homogeneity for each relationship (Hunter and Schmidt 2004). A significant Q-test indicates substantial variance in effect size distribution. The calculated $\mathrm{I}^{2}$ statistic indicates the proportion of variation due to between-study heterogeneity. An $\mathrm{I}^{2}$ value greater than $75 \%$ indicates substantial heterogeneity in effect sizes (Higgins and Thompson 2002). We calculated fail-safe Ns (FSNs) to address the file-drawer problem using the formula suggested by Rosenthal (1979). The FSN is defined as the number of studies needed with null results that lower a significant relationship to a barely significant level. FSNs should be larger than $5 \times \mathrm{k}+$ 10 , with $\mathrm{k}$ being the number of studies (Rosenthal 1979). We calculated an additional funnel plot to assess publication bias; an asymmetric plot indicates potential publication bias. We assessed the robustness of the findings and excluded sample size and effect size outliers from the analyses. Finally, we assessed the power of the tests, with a value greater than .5 indicating sufficient power (Blut et al. 2016).

\section{Structural equation modeling}

The meta-analysis compiled a comprehensive correlation matrix including all variables in the conceptual framework. Where this information was missing, we searched for additional studies, even those that did not include a TR measurement. Meta-studies have regularly employed this approach when developing this matrix (Geyskens et al. 1998). We used this matrix as the input for LISREL 9.2 to calculate an SEM that tested 
interrelationships among variables simultaneously. We used the harmonic mean of all sample sizes in the correlation matrix $(N=1,337)$ as the basis for analysis, since this is more conservative than using the simple mean (Viswesvaran and Ones 1995).

\section{Moderator analysis}

We tested the moderators using a multilevel approach, since effect sizes are nested in different samples. Hox (2010) recommended this approach as it is unlikely that samples reporting multiple measurements are independent of one another. Similar to Pick and Eisend (2016) and Babić Rosario et al. (2016), we used hierarchical linear modeling software to calculate a random-effects model that differentiates between effect size level (level 1) and study level (level 2). We treated the reliability-adjusted correlations as dependent variables and regressed them on the moderators on levels 1 and $2 .{ }^{11}$ This analysis examines only effect sizes that include the TR dimensions as the independent variable and its relationship with a mediator/outcome variable. We propose that the TR inhibitors display negative effect sizes, whereas the motivators show positive ones. To examine the effect sizes of the two TR dimensions together in the moderator analysis, we reversed the reliability-adjusted correlations involving the inhibitors, as Parasuraman (2000) proposed. We also dummy-coded the TR dimensions, mediators, and outcome variables to include them on level 1, as per Hox (2010). According to Cheung (2015), the dummy-coded TR inhibitors and motivators should be tested simultaneously by fixing the model's level 1 intercept to zero; otherwise the model will not be identified (Web Appendix C).

\section{Results}

\section{Descriptive statistics}

Table 3 shows the descriptive results. All motivators (innovativeness, optimism) display significant relationships with antecedents and outcomes, whereas results for inhibitors (insecurity, discomfort) are mixed. ${ }^{12}$ More specifically, the results of the two-dimensional conceptualization suggest that both dimensions are significantly related to technology usage. The effect sizes are small to moderate for motivators ( $\mathrm{rwc}=$ $.18)$ and inhibitors (-.10). Most reported effect sizes are

\footnotetext{
${ }^{11}$ We examined the variance composition of the dependent variable by calculating the intra-class correlation (ICC), which indicates the share of withinstudy variance to total variance (Hox 2010). The ICC is .11, indicating that $89 \%$ of the variance is within studies and $11 \%$ is between studies. Hox (2010) suggested values of $.05, .10$, and .15 as small, medium, and large ICCs, respectively.

12 The descriptive results for the one- and four-dimensional conceptualizations are shown in Web Appendix B.
}

stronger for the motivating than for the inhibiting dimension. There is also an indication of indirect effects of TR through mediators, and antecedent variables seem to be related to TR. Specifically, all variables are significantly related to motivators, with the strongest effects observed for usefulness (.38), ease of use (.37), and satisfaction (.37). The results for the inhibitors are mixed. In total, 6 of 10 effect sizes are significant, with the strongest effects for education (-.29), experience (-.25), and ease of use (-.14).

The wide credibility intervals, most Q-tests of homogeneity, and the $\mathrm{I}^{2}$ statistics $\left(\mathrm{I}^{2}>75 \%\right)$ indicate heterogeneity in the data and the necessity of moderator analysis. All calculated FSNs for the two motivators and inhibitors exceed the tolerance levels suggested by Rosenthal (1979), indicating robustness of the findings against publication bias. The symmetric funnel plot in Web Appendix D suggests that publication bias is unlikely. Exclusion of sample size and effect size outliers does not affect the results. Finally, the power of most tests is sufficient $(>.5)$ to detect meaningful effect sizes.

\section{Results of structural equation modeling}

We use SEM to test the hypotheses, since this considers direct and indirect effects of TR. Calculations are based on the correlation matrices in Web Appendix E-F. The condition number of the SEM is 6.791; thus, multicollinearity is not a serious issue (Jöreskog et al. 2016). We also revised the model displayed in Fig. 1: initially, we assumed all TAM and QVS mediators to directly relate to technology usage and usage intention, as proposed in the literature. However, Palmatier et al. (2007) explained that while various mediators can individually receive empirical support, their relative impacts can only be assessed in a comparative test. We therefore compared several models with a model assuming full mediation using a chi-square difference test. The model fit improves most when considering usefulness and ease of use as key mediators for technology usage $\left(\Delta \chi^{2}=188\right)$, and satisfaction, quality, and ease of use as mediators for behavioral intention $\left(\Delta \chi^{2}=\right.$ $1,393)$. We use the revised model to test our hypotheses (Table 4$){ }^{13}$

SEM results for the integrated TR model indicate strong indirect, rather than direct, effects of the two TR dimensions on technology usage (H1a, H2a). First, motivators are not directly related to usage behavior, but instead exert an influence through the TAM mediators ease of use (H3a; $\beta=.41)$ and usefulness perception ( $\mathrm{H} 4 \mathrm{a} ; \beta=.23)$, but also through the QVS mediators quality (H5a; $\beta=.08$ ), perceived value (H6a;

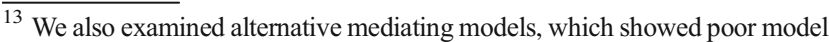
fit. One model considered only the indirect effects of motivators and inhibitors on technology usage through the mediators proposed by QVS literature $\left(\chi_{\mathrm{df}}^{2}=1,409_{(26)} ; \mathrm{CFI}=.68 ; \mathrm{GFI}=.86 ; \mathrm{RMR}=.10 ; \mathrm{SRMR}=.10\right)$. Another assessed their influence only through TAM mediators $\left(\chi_{\mathrm{df}}^{2}=317_{(19)}\right.$; $\mathrm{CFI}=.87 ; \mathrm{GFI}=.95 ; \mathrm{RMR}=.07 ; \mathrm{SRMR}=.07$ ).
} 
Table 2 Operationalization of moderator variables

\begin{tabular}{|c|c|c|}
\hline \# & Variable & Operationalization \\
\hline \multicolumn{3}{|c|}{ Level 1-Moderators } \\
\hline 1 & Ease of use & Dummy-coded whether the effect size includes ease of use as DV (1) or a different variable (0). \\
\hline 2 & Inhibitors & Dummy-coded whether the effect size includes inhibitors as IV (1) or a different variable (0). \\
\hline 3 & Motivators & Dummy-coded whether the effect size includes motivators as IV (1) or a different variable (0). \\
\hline 4 & Usage intention & Dummy-coded whether the effect size includes usage intention as DV (1) or a different variable (0). \\
\hline 5 & Usefulness & Dummy-coded whether the effect size includes usefulness as DV (1) or a different variable (0). \\
\hline 6 & Quality & Dummy-coded whether the effect size includes quality as DV (1) or a different variable (0). \\
\hline 7 & Value & Dummy-coded whether the effect size includes value as DV (1) or a different variable (0). \\
\hline 8 & Satisfaction & Dummy-coded whether the effect size includes satisfaction as DV (1) or a different variable (0). \\
\hline \multicolumn{3}{|c|}{ Level 2-Moderators } \\
\hline 9 & Work technology & Dummy-coded whether the study examines technologies used by employees (1), or consumers $(0)$. \\
\hline 10 & Hedonic technology & Dummy-coded whether the study examines technology satisfying hedonic (1), or utilitarian needs $(0)$. \\
\hline 11 & Voluntariness of use & Dummy-coded whether the technology use in voluntary (1), or mandatory $(0)$. \\
\hline 12 & Firm support & Dummy-coded whether the firms provides customers support (1), or not (0). \\
\hline 13 & GDP & $\begin{array}{l}\text { Gross domestic product per capita (PPP) reported by International Monetary Fund (2017); the meta-analysis uses } \\
\text { the GDP score of the year when the study was published. }\end{array}$ \\
\hline 14 & HDI & $\begin{array}{l}\text { Human development index reported by United Nations (2018), ranging from low (0) to high (1) development; the } \\
\text { meta-analysis uses the HDI score of the year when the study was published. }\end{array}$ \\
\hline 15 & Year & Publication year of the study. \\
\hline 16 & Student sample & Dummy-coded whether the sample is a student (1) or non-student sample (0). \\
\hline 17 & Journal rating & Rating of the publication outlet ranging from high (4) to low (1) (ABS 2015). \\
\hline 18 & Published & Dummy-coded whether the study was published in a journal (1), or not (0). \\
\hline 19 & Previous experience & Dummy-coded whether the customers are novices (1), or not (0). \\
\hline 20 & Uncertainty avoidance & $\begin{array}{l}\text { Hofstede and Hofstede's (2015) country scores for uncertainty avoidance, ranging from low (0) to high (100) } \\
\text { uncertainty avoidance. }\end{array}$ \\
\hline
\end{tabular}

$\beta=-.07)$, and satisfaction ( $\mathrm{H} 7 \mathrm{a} ; \beta=.12)$, as well as intention ( $\mathrm{H} 1 \mathrm{~b} ; \beta=-.07)$. Contrary to predictions, the effects of motivators on perceived value and intentions are negative. ${ }^{14}$

Second, inhibitors also exert strong indirect effects through the TAM mediators ease of use (H3b; $\beta=-.11)$ and usefulness $(\mathrm{H} 4 \mathrm{~b}$; $\beta=.10)$, but also through the QVS mediators quality $(\mathrm{H} 5 \mathrm{~b} ; \beta=$ -.22), perceived value $(\mathrm{H} 6 \mathrm{~b} ; \beta=.16)$, and satisfaction $(\mathrm{H} 7 \mathrm{~b} ; \beta=$ -.09). They are also related to intentions $(\mathrm{H} 2 \mathrm{~b} ; \beta=.17)$. Three effects are contrary to expectations, including the positive effects of inhibitors on usefulness, perceived value, and intention.

Third, the antecedent variable age is negatively related to motivators ( $\mathrm{H} 8 \mathrm{a} ; \beta=-.22$ ), but positively related to inhibitors (H8b; $\beta=.13$ ). Contrarily, customer's education is positively related to motivators ( $\mathrm{H} 9 \mathrm{a} ; \beta=.12$ ), but negatively to inhibitors ( $\mathrm{H} 9 \mathrm{~b} ; \beta=-.25)$. A similar pattern can be observed for the customer's previous experience (H10a, H10b). ${ }^{15}$

Like Pick and Eisend (2014), we tested mediation effects by calculating the indirect and total effects of TR dimensions (Web Appendix G). The total effect of motivators on technology usage (.18) is more than twice as strong as the total effect of inhibitors $(-.07)$. The indirect effect of motivators $(.23)$ is

\footnotetext{
$\overline{14}$ We tested the robustness of this model by comparing it with two models testing the effects of motivators and inhibitors individually. The results are largely identical (13 of 14 TR path estimates $=93 \%)$. The only difference is that the effect of motivators on value is negative in the present model and positive in the alternative model.

${ }^{15}$ The relationship between experience and the two TR dimensions may be recursive. A model with the opposite direction shows worse model fit $\left(\chi_{\mathrm{df}}^{2}=\right.$ $\left.727_{(8)} ; \mathrm{CFI}=.90 ; \mathrm{GFI}=.92 ; \mathrm{RMR}=.04 ; \mathrm{SRMR}=.04\right)$.
}

also much greater than the effect for inhibitors $(-.02)$, leading to indirect effects to total effects ratios of $83 \%$ for motivators and $36 \%$ for inhibitors. These results stress the need to consider mediators in TR research. Finally, we calculated two alternative models assessing the four- and one-dimensional TR conceptualizations. These models show worse fit compared to the two-dimensional model (four dimensions: $\chi_{\mathrm{df}}^{2}=969_{(9)} ; \mathrm{CFI}=.89 ; \mathrm{GFI}=.91 ; \mathrm{RMR}=.09 ; \mathrm{SRMR}=.09$; one dimension: $\chi_{\mathrm{df}}^{2}=1,169_{(3)} ; \mathrm{CFI}=.79 ; \mathrm{GFI}=.89$; $\mathrm{RMR}=.16$; SRMR $=.14$ ). These models did not converge without removing behavioral intention and service quality to improve model fit.

\section{Result of moderator analysis}

Before calculating the multilevel model, we assessed the extent of multicollinearity among level 1 and level 2 variables (Web Appendix H). Since the variance inflation factors are 2.177 for level 1 variables and 5.322 for level 2 variables, multicollinearity is not a serious issue (Babić Rosario et al. 2016). Table 5 shows the moderator results. Similar to previous findings, there are several differences for level 1 variables. The relationships between TR dimensions and technology perception and use are stronger for motivators $(\beta=.25, p<.05)$ than for inhibitors $(\beta=-.01, p>.05)$. Regarding level 2 variables, several contextual characteristics exert an influence on TR effect sizes.

Technology type We tested two classifications characterizing different technologies. Consistent with predictions, 
Table 3 Descriptive statistics for technology readiness construct

\begin{tabular}{|c|c|c|c|c|c|c|c|c|c|c|c|c|c|c|c|c|c|}
\hline Var 1 & Var 2 & $\mathrm{k}$ & $\mathrm{N}$ & $\mathrm{r}$ & Min & Max & rw & rwc & SD & $\mathrm{CI}_{\text {low }}$ & $\mathrm{CI}_{\text {high }}$ & $\mathrm{CR}_{\text {low }}$ & $\mathrm{CR}_{\text {high }}$ & Q & $\mathrm{I}^{2}$ & FSN & Power \\
\hline sage intention $(\mathrm{C})$ & Motivators & 40 & 15,118 & .23 & -.27 & .66 & .23 & $.26^{*}$ & .21 & .20 & .33 & -.01 & .54 & $549 *$ & $93 \%$ & 10,030 & .999 \\
\hline Usefulness (C) & Motivators & 30 & 10,605 & .34 & .00 & .56 & .33 & $.38^{*}$ & .15 & .33 & .44 & .19 & .58 & $203 *$ & $86 \%$ & 9,839 & .999 \\
\hline Ease of use (C) & Motivators & 24 & 8,848 & .33 & .00 & .71 & .32 & $.37 *$ & .16 & .31 & .44 & .17 & .57 & $177 *$ & $87 \%$ & 6,700 & .999 \\
\hline Usage behavior (C) & Motivators & 21 & 9,043 & .18 & -.04 & .72 & .15 & $.18^{*}$ & .17 & .10 & .25 & -.04 & .39 & $196^{*}$ & $90 \%$ & 1,716 & .999 \\
\hline Age (A) & Motivators & 17 & 6,768 & -.12 & -.50 & .28 & -.18 & $-.22 *$ & .18 & -.31 & -.13 & -.45 & .01 & $167 *$ & $90 \%$ & 866 & .999 \\
\hline Satisfaction (C) & Motivators & 13 & 4,777 & .36 & -.03 & .85 & .32 & $.37 *$ & .25 & .23 & .51 & .04 & .69 & $235^{*}$ & $95 \%$ & 2,422 & .999 \\
\hline Education (A) & Motivators & 7 & 3,548 & .14 & .07 & .24 & .15 & $.19^{*}$ & .04 & .14 & .24 & .13 & .25 & 11 & $45 \%$ & 179 & .999 \\
\hline xperience (A) & Motivators & 9 & 2,566 & .25 & .15 & .46 & .25 & $.32 *$ & .04 & .26 & .37 & .26 & .37 & 11 & $26 \%$ & 418 & .999 \\
\hline Quality (C) & Motivators & 9 & 2,352 & .19 & .03 & .33 & .18 & $.21 *$ & .10 & .13 & .29 & .08 & .34 & $26^{*}$ & $70 \%$ & 226 & .999 \\
\hline Value $(\mathrm{C})$ & Motivators & 6 & 1,969 & .12 & .02 & .18 & .13 & $.15^{*}$ & .04 & .09 & .21 & .10 & .20 & 8 & $39 \%$ & 55 & .999 \\
\hline Usage intention (C) & Inhibitors & 28 & 8,567 & -.02 & -.25 & .34 & .01 & .01 & .21 & -.07 & .09 & -.25 & .28 & $285^{*}$ & $91 \%$ & - & .236 \\
\hline Usefulness (C) & Inhibitors & 23 & 7,588 & .04 & -.30 & .38 & .00 & .00 & .16 & -.07 & .07 & -.20 & .21 & $155^{*}$ & $86 \%$ & - & .051 \\
\hline Ease of use (C) & Inhibitors & 19 & 6,123 & -.07 & -.52 & .32 & -.12 & $-.14 *$ & .22 & -.25 & -.04 & -.42 & .14 & $218^{*}$ & $92 \%$ & 377 & .999 \\
\hline ge (A) & nhibitors & 13 & 5,322 & .06 & -.12 & .25 & .10 & $.12^{*}$ & .14 & .04 & .20 & -.06 & .29 & $71 *$ & $83 \%$ & 140 & .999 \\
\hline sage behavior $(\mathrm{C})$ & Inhibitors & 12 & 5,233 & -.04 & -.23 & .33 & -.08 & $-.10^{*}$ & .14 & -.18 & -.01 & -.27 & .08 & $71 *$ & $85 \%$ & 66 & .999 \\
\hline atisfaction (C) & Inhibitors & 7 & 2,548 & -.15 & -.83 & .28 & -.13 & -.15 & .35 & -.42 & .11 & -.60 & .29 & $198 *$ & $97 \%$ & - & .999 \\
\hline Education (A) & Inhibitors & 6 & 3,298 & -.21 & -.28 & -.03 & -.22 & $-.29 *$ & .10 & -.38 & -.20 & -.41 & -.17 & $23 *$ & $78 \%$ & 317 & .999 \\
\hline Experience (A) & Inhibitors & 6 & 2,268 & -.13 & -.25 & -.01 & -.19 & $-.25^{*}$ & .08 & -.34 & -.17 & -.36 & -.15 & $14^{*}$ & $65 \%$ & 111 & .999 \\
\hline Quality (C) & Inhibitors & 2 & 915 & -.13 & -.26 & .01 & -.16 & -.20 & .16 & -.43 & .04 & -.40 & .01 & $17 *$ & $94 \%$ & - & .999 \\
\hline Value $(\mathrm{C})$ & Inhibitors & 1 & 330 & .02 & .02 & .02 & .02 & $.02 *$ & .00 & .02 & .02 & .02 & .02 & - & - & - & .100 \\
\hline
\end{tabular}

$\mathrm{A}=$ antecedent $\mathrm{C}=$ consequence $\mathrm{k}=$ number of effect sizes; $\mathrm{N}=$ cumulative sample size; $\mathrm{r}=$ observed average correlation; Min $=$ minimum observed correlation; Max = maximum observed correlation; rw = sample-weighted average correlation; rwc = sample-weighted reliability adjusted average correlation; $\mathrm{CI}=95 \%$-confidence interval; $\mathrm{CR}=80 \%$ credibility interval; $\mathrm{Q}=\mathrm{Q}$ statistic; $\mathrm{I}^{2} \mathrm{I}^{2}$-statistic; $\mathrm{FSN}=$ fail-safe N; Power $=$ power test using N as sample size. $* p<.05$ (rwc: two-tailed)

TR motivators display stronger effects on technology perception and use for hedonic technologies (H12a; $\beta=.12$ ), whereas inhibitors display stronger effects for utilitarian technologies (H12b; $\beta=-.15)$. No differences were observed for technologies used at work versus at home $(\mathrm{H} 11 ; p>.05)$. The hedonic/utilitarian classification apparently performs better since it assesses technologies from the customer's viewpoint.

Firm characteristics As predicted, the motivators gain relevance for explaining technology perception and use in voluntary use contexts $(\mathrm{H} 13 \mathrm{a} ; \beta=.10)$. No significant effect was observed for inhibitors (H13b). While firm support was found to interact with motivators on technology perception and use $(\mathrm{H} 14 \mathrm{a} ; \beta=.10)$, no difference was observed for inhibitors. We observed stronger effects of motivators when customers receive support.

Country characteristics There are consistent patterns for the country's GDP and HDI, in line with predictions. Specifically, motivators $(\mathrm{H} 16 \mathrm{a} ; \beta=.01)$ display stronger effects on technology perception and use in high-GDP countries, whereas the opposite applies for inhibitors (H16b; $\beta=-.01)$. Regarding country development, motivators (H17a; $\beta=-1.10)$ display weaker effects on technology perception and use in high-HDI countries, whereas inhibitors $(\mathrm{H} 17 \mathrm{~b} ; \beta=1.78)$ display stronger effects as HDI increases.

Controls We did not observe any specific pattern for the examined control variables because we only found two significant effects. While study year increases motivator effects on technology perception and use $(\beta=.02)$, we found weaker effects of inhibitors in student samples $(\beta=-.12)$. Publication outlet quality is not significant. Furthermore, we did not observe publication status to moderate relationships; thus, there is no difference between published and unpublished studies. No differences were observed for novice compared to expert customers. Previous experience appears to exert a direct effect on TR, rather than a moderating effect. Uncertainty avoidance is also not significant.

Additional analysis Although not hypothesized, we assessed the moderating effect of study year on the age-TR relationship, since during the last 20 years all ages, including older generations, have become more familiar with technology. Thus, the age-TR relationship 
Table 4 Results of structural equation modeling

\begin{tabular}{|c|c|c|}
\hline Relationship & $\mathrm{B}$ & $\mathrm{R}^{2}$ \\
\hline \multicolumn{3}{|l|}{ Consequences } \\
\hline Usage intention $\rightarrow$ Usage behavior & $.10 *$ & \multirow[t]{8}{*}{$24 \%$} \\
\hline Usefulness $\rightarrow$ Usage behavior & $.17 *$ & \\
\hline Ease of use $\rightarrow$ Usage behavior & $.31 *$ & \\
\hline Education $\rightarrow$ Usage behavior & $.07 *$ & \\
\hline Experience $\rightarrow$ Usage behavior & -.01 & \\
\hline Age $\rightarrow$ Usage behavior & -.03 & \\
\hline Motivators $\rightarrow$ Usage behavior (H1a) & -.05 & \\
\hline Inhibitors $\rightarrow$ Usage behavior (H2a) & -.04 & \\
\hline Satisfaction $\rightarrow$ Usage intention & $.67^{*}$ & \multirow[t]{8}{*}{$68 \%$} \\
\hline Quality $\rightarrow$ Usage intention & $.17 *$ & \\
\hline Ease of use $\rightarrow$ Usage intention & $.20 *$ & \\
\hline Education $\rightarrow$ Usage intention & $.14 *$ & \\
\hline Experience $\rightarrow$ Usage intention & $-.16^{*}$ & \\
\hline Age $\rightarrow$ Usage intention & $-.08 *$ & \\
\hline Motivators $\rightarrow$ Usage intention (H1b) & $-.07 *$ & \\
\hline Inhibitors $\rightarrow$ Usage intention (H2b) & $.17^{*}$ & \\
\hline Value $\rightarrow$ Satisfaction & $.30^{*}$ & \multirow{9}{*}{$68 \%$} \\
\hline Quality $\rightarrow$ Satisfaction & $.44 *$ & \\
\hline Usefulness $\rightarrow$ Satisfaction & $.14 *$ & \\
\hline Ease of use $\rightarrow$ Satisfaction & $.16^{*}$ & \\
\hline Education $\rightarrow$ Satisfaction & $-.34 *$ & \\
\hline Experience $\rightarrow$ Satisfaction & $.19^{*}$ & \\
\hline Age $\rightarrow$ Satisfaction & .02 & \\
\hline Motivators $\rightarrow$ Satisfaction (H7a) & $.12 *$ & \\
\hline Inhibitors $\rightarrow$ Satisfaction (H7b) & $-.09 *$ & \\
\hline Quality $\rightarrow$ Value & $.55^{*}$ & \multirow[t]{8}{*}{$43 \%$} \\
\hline Usefulness $\rightarrow$ Value & $-.13 *$ & \\
\hline Ease of use $\rightarrow$ Value & $.59 *$ & \\
\hline Education $\rightarrow$ Value & $-.08 *$ & \\
\hline Experience $\rightarrow$ Value & $-.10 *$ & \\
\hline Age $\rightarrow$ Value & -.01 & \\
\hline Motivators $\rightarrow$ Value (H6a) & $-.07 *$ & \\
\hline Inhibitors $\rightarrow$ Value (H6b) & $.16^{*}$ & \\
\hline Usefulness $\rightarrow$ Quality & $.71 *$ & \multirow[t]{7}{*}{$53 \%$} \\
\hline Ease of use $\rightarrow$ Quality & $-.45^{*}$ & \\
\hline Education $\rightarrow$ Quality & $.15^{*}$ & \\
\hline Experience $\rightarrow$ Quality & $.04 *$ & \\
\hline Age $\rightarrow$ Quality & $.19^{*}$ & \\
\hline Motivators $\rightarrow$ Quality (H5a) & $.08 *$ & \\
\hline Inhibitors $\rightarrow$ Quality (H5b) & $-.22 *$ & \\
\hline Ease of use $\rightarrow$ Usefulness & $.45^{*}$ & \multirow[t]{6}{*}{$34 \%$} \\
\hline Education $\rightarrow$ Usefulness & $.10^{*}$ & \\
\hline Experience $\rightarrow$ Usefulness & -.04 & \\
\hline Age $\rightarrow$ Usefulness & .05 & \\
\hline Motivators $\rightarrow$ Usefulness (H4a) & $.23 *$ & \\
\hline Inhibitors $\rightarrow$ Usefulness (H4b) & $.10^{*}$ & \\
\hline Education $\rightarrow$ Ease of use & $.10^{*}$ & \multirow[t]{5}{*}{$18 \%$} \\
\hline Experience $\rightarrow$ Ease of use & $-.19 *$ & \\
\hline Age $\rightarrow$ Ease of use & .04 & \\
\hline Motivators $\rightarrow$ Ease of use (H3a) & $.41 *$ & \\
\hline Inhibitors $\rightarrow$ Ease of use (H3b) & $-.11 *$ & \\
\hline \multicolumn{3}{|l|}{ Antecedents } \\
\hline Age $\rightarrow$ Motivators (H8a) & $-.22 *$ & \multirow[t]{3}{*}{$16 \%$} \\
\hline Education $\rightarrow$ Motivators (H9a) & $.12 *$ & \\
\hline Experience $\rightarrow$ Motivators (H10a) & $.27^{*}$ & \\
\hline Age $\rightarrow$ Inhibitors (H8b) & $.13^{*}$ & \multirow[t]{2}{*}{$13 \%$} \\
\hline Education $\rightarrow$ Inhibitors (H9b) & $-.25 *$ & \\
\hline Experience $\rightarrow$ Inhibitors (H10b) & $-.16^{*}$ & \\
\hline
\end{tabular}

$* \mathrm{p}<.05$ (two-tailed). Model fit: $\chi_{\mathrm{df}}^{2}=636_{(6)} ; \mathrm{CFI}=.91 ; \mathrm{GFI}=.93$; $\mathrm{RMR}=.03 ; \mathrm{SRMR}=.03$

may have weakened over time. Using a similar multilevel approach as before (Web Appendix I), we found that study year did not moderate any relationship, for either the age-motivators $(\beta=.02, p>.05)$ or the ageinhibitors $(\beta=.00, \mathrm{p}>.05)$ relationship.

\section{Discussion}

We conducted a meta-analysis examining the TR-technology usage relationship, because marketers widely use the TR index to guide technology introduction in the customer-firm relationship (Parasuraman and Colby 2015). The present meta-analysis enhances understanding of the TR construct and its role in marketing and serving customers. Specifically, we aimed to improve understanding of the construct by investigating its dimensionality, and assessing mediating mechanisms and moderating influences in the TR-technology usage relationship. First, although marketing scholars frequently use TR to understand customers' general views on technology, the literature is unclear on how to conceptualize and measure the construct. The meta-study clarifies that the construct is best conceptualized as two-dimensional, differentiating between TR motivators (innovativeness, optimism) and inhibitors (insecurity, discomfort). This conceptualization had the best model fit (Table 4), and should be used in marketing research since it outperforms alternative conceptualizations. This intermediate model apparently represents an excellent compromise between an overly general but simpler model (one dimension) and a more complete but complex alternative (four dimensions). While similar tests have been conducted for other trait variables, marketing literature was lacking guidance regarding the TR construct.

Second, marketing scholars use the TR index to identify and characterize customers that are less likely to use a specific technology and to experience problems. The meta-study therefore examined the TR-technology usage relationship because previous studies have reported inconsistent findings, with some reporting an effect and others reporting no effect (Table 3). We use a comprehensive database to clarify that TR actually impacts technology use, but find that the effect of TR on usage behavior is indirect, through mediators, rather than direct. Scholars should therefore consider this trait variable when studying technology usage, but they must consider mediators. The results also suggest stronger relationships for TR motivators compared to inhibitors. Scholars should therefore differentiate between the two dimensions in their models, and always consider both when examining technology usage.

Third, while some studies in the marketing literature have considered mediators when studying TR effects, others have not, or have only examined some of the many potential mediators. The meta-study therefore assessed the role of several mediators proposed by two literature streams. The two TR dimensions relate to perceived quality, value, and satisfaction, as marketing literature has suggested, alongside ease of use and usefulness, as per technology acceptance literature. The results suggest that the five mediators should be examined jointly in one model when studying technology use, since both TR dimensions are positively related to all mediators. We also find that TAM mediators are more strongly related to 
Table 5 Results of moderator analysis

\begin{tabular}{|c|c|c|c|}
\hline Predictors & Unstandardized Estimates & t-ratio & $p$ value \\
\hline \multicolumn{4}{|l|}{ Level 1-Effects } \\
\hline Motivators & $.25^{*}$ & 8.38 & .00 \\
\hline Inhibitors & -.01 & .31 & .76 \\
\hline Ease of use & $.11^{*}$ & 2.79 & .01 \\
\hline Usefulness & .06 & 1.53 & .13 \\
\hline Satisfaction & $.11^{*}$ & 2.29 & .02 \\
\hline Value & -.08 & 1.13 & .26 \\
\hline Quality & .04 & .79 & .43 \\
\hline Usage intention & .03 & .88 & .38 \\
\hline \multicolumn{4}{|l|}{ Level 2-Effects } \\
\hline \multicolumn{4}{|l|}{ Motivators-Interactions } \\
\hline Work technology (H11a) & .05 & 1.31 & .19 \\
\hline Hedonic technology (H12a) & $.12 *$ & 3.38 & .00 \\
\hline Voluntariness of use (H13a) & $.10 *$ & 3.24 & .00 \\
\hline Firm support (H14a/15a) & $.10 *$ & 3.12 & .00 \\
\hline GDP (H16a) & $.01 *$ & 2.27 & .02 \\
\hline HDI (H17a) & $-1.10 *$ & 3.35 & .00 \\
\hline Year & $.02 *$ & 3.63 & .00 \\
\hline Student & -.04 & 1.07 & .29 \\
\hline Journal rating & -.01 & .08 & .93 \\
\hline Published & -.08 & 1.70 & .09 \\
\hline Previous experience & -.04 & 1.44 & .15 \\
\hline Uncertainty avoidance & -.01 & 1.31 & .19 \\
\hline \multicolumn{4}{|l|}{ Inhibitors-Interactions } \\
\hline Work technology (H11b) & -.08 & 1.60 & .11 \\
\hline Hedonic technology (H12b) & $-.15^{*}$ & 3.45 & .00 \\
\hline Voluntariness of use (H13b) & -.07 & 1.70 & .09 \\
\hline Firm support (H14b/15b) & -.06 & 1.33 & .19 \\
\hline GDP $(\mathrm{H} 16 \mathrm{~b})$ & $-.01 *$ & 2.37 & .02 \\
\hline HDI (H17b) & $1.78^{*}$ & 4.71 & .00 \\
\hline Year & .01 & .51 & .61 \\
\hline Student & $-.12 *$ & 2.51 & .01 \\
\hline Journal rating & -.01 & .83 & .41 \\
\hline Published & .01 & .14 & .89 \\
\hline Previous experience & -.05 & 1.25 & .21 \\
\hline Uncertainty avoidance & -.01 & 1.75 & .08 \\
\hline
\end{tabular}

The dependent variable is the reliability corrected correlation which was reversed for inhibitors to ensure that all correlations show the same direction. The ICC is $11 \%$. A negative (positive) interaction indicates that the predictor loses (gains) relevance the higher the moderator. For example, the positive effect of hedonic technology (H12a, $\beta=.12$ ) suggests that the effect sizes between motivators and mediators/outcomes are stronger for hedonic than utilitarian technologies. $* \mathrm{p}<.05$ (two-tailed) technology usage, whereas QVS mediators are related to usage intention. Thus, marketing scholars should always consider mediators discussed in the TAM literature. However, the indirect effect of motivators on technology usage is stronger than the indirect effects of inhibitors (Web Appendix G). Also, the higher ratio of indirect to total effects suggests that mediators are more essential for understanding motivators than inhibitors. Customers apparently consider their general beliefs about the positives of technology more strongly when assessing a specific technology, rather than their beliefs about disadvantages. Some direct effects of both TR dimensions on mediators/outcomes are contrary to our expectations (Table 4). The meta-study by Blut et al. (2016) made similar observations for other technology beliefs, and emphasized the need for more qualitative research exploring the underlying reasons.

Fourth, the meta-study aimed to guide marketing scholars regarding contexts in which TR effects are most central in explaining technology usage, and how to explain inconsistent findings related to TR in empirical studies. We therefore examined several moderator variables to assess when TR dimensions relate to technology usage. For technology types, we find motivators to be more relevant for hedonic technologies, and inhibitors for utilitarian technologies. Thus, marketing scholars should consider different TR dimensions for these technology types. The differential effects therefore may explain why some studies have found the TR dimensions to be of lesser importance. This technology classification also performs better in explaining the variation of TR effects, compared to the work/home distinction proposed in established acceptance theories (Venkatesh et al. 2012). We also find some firm characteristics to display moderating influences. The TR motivators gain importance in voluntary technology use contexts, which is consistent with technology acceptance literature. In voluntary use contexts customers' general technology beliefs determine their behavior, whereas in mandatory settings it is the coercive environment that makes customers use technology. Because no significant effect was observed for inhibitors, inhibitors apparently exert the same influence on technology usage independent of voluntariness. Even in 
mandatory settings the customers' negative beliefs (i.e., inhibitors) matter, and customers refuse to use the technology. Thus, marketing scholars should also consider voluntariness an essential moderator in explaining when certain technology beliefs impact usage. Moreover, we find a positive interaction effect between firm support and TR motivators. TR motivators are more likely to improve technology perception and use when customers receive support. Thus, not only must customers display a high TR, but they often need additional firm support to use technology. No effect was observed for inhibitors; evidently, firm support is often insufficient to help customers cope with insecurity and discomfort. Scholars should examine whether the results hold for different types of firm support. Finally, we find the country context to moderate TR effects. Thus, marketing scholars should reconsider their knowledge about TR's role for technology use in different countries. Because we find strong and consistent moderating effects of the country's economic situation (GDP, HDI), TR research should consider these characteristics when examining TR in different country settings (Westjohn et al. 2009). Palmatier et al. $(2018$, p. 2) explained that testing such moderators helps clarify "inconsistencies in prior results and [provides] potential explanations." It also guides scholars on when to consider TR as an antecedent of technology usage.

Finally, this study provides marketing scholars with insights into the antecedents of TR that are related to technology use through TR. We find that customers' sociodemographic characteristics are associated with the two TR dimensions. Prior research on antecedents has been mixed (Gilly et al. 2012). This meta-study clarifies that scholars should consider these variables to characterize TR segments. Using traitformation theory to explain these effects, the meta-analysis provides TR research with a new theoretical perspective (Anastasi 1983).

\section{Managerial implications}

Due to the growing role of technology for service provision, customers must increasingly interact with new technologies rather than company personnel (Parasuraman and Colby 2015). This study has several practical implications for marketing managers considering introducing these technologies, and for effective management of the customer-technology link. First, managers are encouraged to use TR to segment markets and identify potential technology users. When conducting market research, managers usually have to choose between different trait models (e.g., the five-factor personality model) to characterize different target segments. Using a specific model for segmentation requires it to have behavioral relevance and to impact customer perceptions. Our study makes a strong case for using the TR model for this purpose, since it explains technology perception and use well.
Second, we provide managers responsible for market research with guidance regarding measuring TR in these assessments. While some marketing managers have previously used only the 10-item overall TR measure, we clearly show that they should use measures for both TR dimensions, motivators and inhibitors, to ensure that firms assess the readiness of their customers accurately. Managers should use these two dimensions to assess, for example, how the firm's customer base compares with the general public's TR, or whether distinct segments in the customer base differ regarding these two dimensions.

Third, firms must consider TR when designing technology interfaces, since some customers are less likely to evaluate the technology's usefulness and ease of use favorably. Managers should emphasize communication of these technology benefits to problematic target markets. Additionally, customers have different quality, value, and satisfaction assessments of technology. Thus, service firms introducing technologies to mass markets must educate customers about the benefits, otherwise customers only rely on their general technology beliefs when deciding about technology use. Firms should design incentive systems to encourage individuals with a natural inclination to avoid using technology.

Fourth, marketing managers often decide to provide service customers with support during technology use to assist when problems arise with the customertechnology interface. Our study suggests that firm support does not mitigate the adverse effects of individual differences in TR. Instead, customers high in TR benefit more from support than do customers low in TR. We also find that voluntariness impacts customers' reliance on general technology beliefs. When customers are coerced to use technology, they do not rely on these beliefs to the same extent compared to voluntary settings. Thus, service firms can disregard the TR of customers in these contexts in the short run.

Fifth, our study provides guidance about contexts in which the impact of inhibitors is suppressed and acceptance enablers are promoted. Managers offering hedonic (utilitarian) technologies should focus less on TR inhibitors (motivators), since customers do not consider these in decision making, and more on TR motivators (inhibitors). Managers need not differentiate between work/ home technology markets because TR has the same effect on technology use in these contexts.

Sixth, our study has implications for international marketing. Service firms nowadays often attempt to target low-income customers in emerging markets (Arunachalam et al. 2019), since "emerging markets [...] provide a plethora of growth opportunities and are slated to grow almost three times faster than the developed economies" (Kumar et al. 2015, p. 627). It 
is therefore unsurprising that U.S. bank JPMorgan Chase operates in over 60 countries, serving clients globally. The bank must consider carefully to which customers it will offer technologies such as online and mobile banking. Similar firms should use countries' GDP and HDI to assess the importance of TR in different markets.

Finally, we advise marketing managers regarding use of demographic characteristics that distinguish customers who are high/low in TR from those who are not. Recently, managers may have gained the impression that more customers have become tech-savvy than in the past, making customer age lose relevance for characterizing customers' TR. Our study clarifies that age is negatively related to TR motivators, while education and experience are positively related to motivators. We find the opposite effects for inhibitors. Importantly, the age-TR relationship is stable and has not changed in recent years. Thus, managers can still use this demographic variable to characterize different TR segments.

\section{Limitations and further research}

Like most methods, meta-analyses have certain limitations that future research should address. The study is restricted regarding data availability, and relies on data from existing studies. First, the research assesses the relationship between TR and several mediator and outcome variables from two literature streams. There are fewer effect sizes for the inhibitors-value relationship in the data than for other relationships. Additionally, future research should assess these effects of TR together with other constructs that key theories propose, such as the TAM's consideration of social influence.

Second, we find differences in effects across TR dimensions. Specifically, some of the TR dimensions display a different effect on mediators, as initially predicted. We speculate about reasons for these differences, but meta-analyses do not provide insights into "why" certain effects occur. Qualitative studies may provide more explanations thereon.

Third, we tested various moderators characterizing the study context. Future research could test not only more individual-level moderators, but also whether certain moderating variables - such as GDP and HDI - exert additional direct effects on TR, which should be tested when more effect sizes are available.

Finally, we find that three antecedent variables are related to TR. Future research should continue to study these variables. For example, the relationship between experience and TR may be recursive, with TR influencing experience. Scholars should conduct longitudinal studies on TR to determine the relationship's direction. It would also be interesting to conduct a technology anxiety meta-analysis with the same antecedents, mediators, and outcomes to assess the differences between both trait variables.
Open Access This article is distributed under the terms of the Creative Commons Attribution 4.0 International License (http:// creativecommons.org/licenses/by/4.0/), which permits unrestricted use, distribution, and reproduction in any medium, provided you give appropriate credit to the original author(s) and the source, provide a link to the Creative Commons license, and indicate if changes were made.

\section{References}

ABS. (2015). Academic Journal Guide. London: Chartered Association of Business Schools.

Agarwal, R., \& Prasad, J. (1998). A conceptual and operational definition of personal innovativeness in the domain of information technology. Information Systems Research, 9(2), 204-215.

Ajzen, I., \& Fishbein, M. (2005). The influence of attitudes on behavior. The Handbook of Attitudes, in D. Albarracin, B. T. et al. (eds.), Mahwah, NJ: Erlbaum, pp. 173-221.

Alba, J. W., \& Hutchinson, J. W. (1987). Dimensions of consumer expertise. Journal of Consumer Research, 13(4), 411-454.

Anastasi, A. (1983). Evolving trait concepts. American Psychologist, $38(2), 175-184$

Arcelus, F., Sharma, B., \& Srinivasan, G. (2005). Assessing the information content of the technology achievement index in the presence of the human development index. Economics Bulletin, 15(4), 1-5.

Arunachalam, S., Bahadir, S. C., Bharadwaj, S. G., \& Guesalaga, R. (2019). New product introductions for low-income consumers in emerging markets. Journal of the Academy of Marketing Science, $1-27$.

Auer, J., \& Papies, D. (2019). Cross-price elasticities and their determinants: A meta-analysis and new empirical generalizations. Journal of the Academy of Marketing Science. https://doi.org/10.1007/ s11747-019-00642-0.

Ayyagari, R., Grover, V., \& Purvis, R. (2011). Technostress: Technological antecedents and implications. MIS Quarterly, 35(4), 831-858.

Babin, B. J., Darden, W. R., \& Griffin, M. (1994). Work and/or fun: Measuring hedonic and utilitarian shopping value. Journal of Consumer Research, 20(4), 644-656.

Babić Rosario, A., Sotgiu, F., De Valck, K., \& Bijmolt, T. H. (2016). The effect of electronic word of mouth on sales: A meta-analytic review of platform, product, and metric factors. Journal of Marketing Research, 53(3), 297-318.

Barrutia, J. M., \& Gilsanz, A. (2013). Electronic service quality and value: Do consumer knowledge-related resources matter? Journal of Service Research, 16(2), 231-246.

Berry, H., Guillén, M. F., \& Zhou, N. (2010). An institutional approach to cross-national distance. Journal of International Business Studies, 41(9), 1460-1480.

Blut, M., Wang, C., \& Schoefer, K. (2016). Factors influencing the acceptance of self-service technologies: A meta-analysis. Journal of Service Research, 19(4), 396-416.

Burgess, S. M., \& Steenkamp, J. B. E. (2006). Marketing renaissance: How research in emerging markets advances marketing science and practice. International Journal of Research in Marketing, 23(4), $337-356$

Carrillat, F. A., Legoux, R., \& Hadida, A. L. (2018). Debates and assumptions about motion picture performance: A meta-analysis. Journal of the Academy of Marketing Science, 46(2), 273-299.

Chen, S. C., Chen, H. H., \& Chen, M. F. (2009). Determinants of satisfaction and continuance intention towards self-service technologies. Industrial Management and Data Systems, 109(9), 1248-1263.

Cheung, M. W. L. (2015). Meta-analysis: A structural equation modeling approach. John Wiley \& Sons. 
Claudy, M. C., Garcia, R., \& O’Driscoll, A. (2015). Consumer resistance to innovation-A behavioral reasoning perspective. Journal of the Academy of Marketing Science, 43(4), 528-544.

Collier, J. E., \& Sherrell, D. L. (2010). Examining the influence of control and convenience in a self-service setting. Journal of the Academy of Marketing Science, 38(4), 490-509.

Cronin, J. J., Jr., Brady, M. K., \& Hult, G. T. M. (2000). Assessing the effects of quality, value, and customer satisfaction on consumer behavioral intentions in service environments. Journal of Retailing, 76(2), 193-218.

Dabholkar, P. A. (1996). Consumer evaluations of new technology-based self-service options: An investigation of alternative models of service quality. International Journal of Research in Marketing, 13(1), 29-51.

Dabholkar, P. A., \& Bagozzi, R. P. (2002). An attitudinal model of technology-based self-service: Moderating effects of consumer traits and situational factors. Journal of the Academy of Marketing Science, 30(3), 184-201.

Davis, F. D., Bagozzi, R. P., \& Warshaw, P. R. (1989). User acceptance of computer technology: A comparison of two theoretical models. Management Science, 35(8), 982-1003.

Dutot, V. (2014). Adoption of social media using technology acceptance model: The generational effect. International Journal of Technology and Human Interaction, 10(4), 18-35.

Eisend, M. (2010). A meta-analysis of gender roles in advertising. Journal of the Academy of Marketing Science, 38(4), 418-440.

Geyskens, I., Steenkamp, J. B. E. M., \& Kumar, N. (1998). Generalizations about trust in marketing channel relationships using meta-analysis. International Journal of Research in Marketing, 15(3), 223-248.

Giebelhausen, M., Robinson, S. G., Sirianni, N. J., \& Brady, M. K. (2014). Touch versus tech: When technology functions as a barrier or a benefit to service encounters. Journal of Marketing, 78(4), 113124

Gilly, M. C., Celsi, M. W., \& Schau, H. J. (2012). It don’t come easy: Overcoming obstacles to technology use within a resistant consumer group. Journal of Consumer Affairs, 46(1), 62-89.

Goldsmith, R. E., \& Hofacker, C. F. (1991). Measuring consumer innovativeness. Journal of the Academy of Marketing Science, 19(3), 209-221

Hartwick, J., \& Barki, H. (1994). Explaining the role of user participation in information system use. Management Science, 40(4), 440-465.

Higgins, J. P., \& Thompson, S. G. (2002). Quantifying heterogeneity in a meta-analysis. Statistics in Medicine, 21(11), 1539-1558.

Hirschman, E. C. (1980). Innovativeness, novelty seeking, and consumer creativity. Journal of Consumer Research, 7(3), 283-295.

Hofstede, G. H. \& Hofstede, G. J. (2015). Dimension data matrix. (accessed March 13, 2019). [available at http://www.geerthofstede.com].

Homburg, C., Wieseke, J., \& Kuehnl, C. (2010). Social influence on salespeople's adoption of sales technology: A multilevel analysis. Journal of the Academy of Marketing Science, 38(2), 159-168.

Hox, J. J. (2010). Multilevel analysis: Techniques and applications. New York: Routledge.

Hunter, J. E., \& Schmidt, F. L. (2004). Methods of meta-analysis (2nd ed.). Thousand Oaks, CA: Sage Publications.

Hur, H. J., Lee, H. K., \& Choo, H. J. (2017). Understanding usage intention in innovative mobile app service: Comparison between millennial and mature consumers. Computers in Human Behavior, 73, 353-361.

Hwang, J., \& Good, L. (2014). Intelligent sensor-based services success: The role of consumer characteristics and information. European Journal of Marketing, 48(3/4), 406-431.

International Monetary Fund (2017). World economic outlook database. (accessed November 14, 2017). [available at http://www.imf.org/]
Jin, C. (2013). The perspective of a revised TRAM on social capital building: The case of Facebook usage. Information and Management, 50(4), 162-168.

Johnson, D. S., Bardhi, F., \& Dunn, D. T. (2008). Understanding how technology paradoxes affect customer satisfaction with self-service technology: The role of performance ambiguity and trust in technology. Psychology and Marketing, 25(5), 416-443.

Jöreskog, K. G., Olsson, U. H., \& Y Wallentin, F. (2016). Multivariate analysis with LISREL. Springer International Publishing.

Kumar, V., Nim, N., \& Sharma, A. (2018). Driving growth of Mwallets in emerging markets: A retailer's perspective. Journal of the Academy of Marketing Science, 47, 770. https://doi.org/10.1007/s11747-01800623-9.

Kumar, V., Sunder, S., \& Sharma, A. (2015). Leveraging distribution to maximize firm performance in emerging markets. Journal of Retailing, 91(4), 627-643.

Lam, S. Y., Chiang, J., \& Parasuraman, A. (2008). The effects of the dimensions of technology readiness on technology acceptance: An empirical analysis. Journal of Interactive Marketing, 22(4), 19-39.

Liljander, V., Gillberg, F., Gummerus, J., \& Van Riel, A. (2006). Technology readiness and the evaluation and adoption of selfservice technologies. Journal of Retailing and Consumer Services, 13(3), 177-191.

Maier, E. (2016). Supply and demand on crowdlending platforms: Connecting small and medium-sized enterprise borrowers and consumer investors. Journal of Retailing and Consumer Services, 33, $143-153$.

Maslow, A. H. (1954). The instinctoid nature of basic needs. Journal of Personality, 22(3), 326-347.

Massey, A. P., Khatri, V., \& Minas, R. K. (2013). The influence of psychographic beliefs on website usability requirements. AIS Transactions on Human-Computer Interaction, 5(4), 157-174.

Meuter, M. L., Ostrom, A. L., Bitner, M. J., \& Roundtree, R. (2003). The influence of technology anxiety on consumer use and experiences with self-service technologies. Journal of Business Research, 56(11), 899-906.

Meuter, M. L., Bitner, M. J., Ostrom, A. L., \& Brown, S. W. (2005). Choosing among alternative service delivery modes: An investigation of customer trial of self-service technologies. Journal of Marketing, 69(2), 61-83.

Mick, D. G., \& Fournier, S. (1998). Paradoxes of technology: Consumer cognizance, emotions, \& coping strategies. Journal of Consumer Research, 25(2), 123-143.

Midgley, D. F., \& Dowling, G. R. (1978). Innovativeness: The concept and its measurement. Journal of Consumer Research, 4(4), 229242.

Montoya-Weiss, M. M., Voss, G. B., \& Grewal, D. (2003). Determinants of online channel use and overall satisfaction with a relational, multichannel service provider. Journal of the Academy of Marketing Science, 31(4), 448-458.

Mowen, J. C. (2000). The 3M model of motivation and personality: Theory and empirical applications to consumer behavior. Springer Science \& Business Media.

Nysveen, H., Pedersen, P. E., \& Thorbjørnsen, H. (2005). Intentions to use mobile services: Antecedents and cross-service comparisons. Journal of the Academy of Marketing Science, 33(3), 330-346.

Palmatier, R. W., Dant, R. P., \& Grewal, D. (2007). A comparative longitudinal analysis of theoretical perspectives of Interorganizational relationship performance. Journal of Marketing, 71(4), 172-194.

Palmatier, R. W., Dant, R. P., Grewal, D., \& Evans, K. R. (2006). Factors influencing the effectiveness of relationship marketing: A metaanalysis. Journal of Marketing, 70(4), 136-153.

Palmatier, R. W., Houston, M. B., \& Hulland, J. (2018). Review articles: Purpose, process, and structure. Journal of the Academy of Marketing Science, 46(1), 1-5. 
Parasuraman, A. (2000). Technology readiness index (TRI) a multipleitem scale to measure readiness to embrace new technologies. Journal of Service Research, 2(4), 307-320.

Parasuraman, A., \& Colby, C. L. (2015). An updated and streamlined technology readiness index: TRI 2.0. Journal of Service Research, 18(1), 59-74.

Parasuraman, A., \& Grewal, D. (2000). The impact of technology on the quality-value-loyalty chain: A research agenda. Journal of the Academy of Marketing Science, 28(1), 168-174.

Peterson, R. A. (2001). On the use of college students in social science research: Insights from a second-order meta-analysis. Journal of Consumer Research, 28, 450-461.

Peterson, R. A., \& Brown, S. P. (2005). On the use of beta coefficients in meta-analysis. Journal of Applied Psychology, 90(1), 175-181.

Pick, D., \& Eisend, M. (2014). Buyers' perceived switching costs and switching: A meta-analytic assessment of their antecedents. Journal of the Academy of Marketing Science, 42(2), 186-204.

Pick, D., \& Eisend, M. (2016). Customer responses to switching costs: A meta-analytic investigation of the moderating influence of culture. Journal of International Marketing, 24(4), 39-60.

Rahman, S. A., Taghizadeh, S. K., Ramayah, T., \& Alam, M. M. D. (2017). Technology acceptance among micro-entrepreneurs in marginalized social strata: The case of social innovation in Bangladesh. Technological Forecasting and Social Change, 118, 236-245.

Rogers, E. M. (1995). Diffusion of innovations (4th ed.). New York, NY: Free Press.

Rojas-Méndez, J. I., Parasuraman, A., \& Papadopoulos, N. (2017). Demographics, attitudes, and technology readiness: A crosscultural analysis and model validation. Marketing Intelligence and Planning, 35(1), 18-39.

Rosenthal, R. (1979). The 'file-drawer problem' and tolerance for null results. Psychological Bulletin, 86(3), 638-641.

Sääksjärvi, M., \& Samiee, S. (2011). Assessing multifunctional innovation adoption via an integrative model. Journal of the Academy of Marketing Science, 39(5), 717-735.

Sheth, J. N. (2011). Impact of emerging markets on marketing: Rethinking existing perspectives and practices. Journal of Marketing, 75(4), 166-182.

Sheth, J. N., Newman, B. I., \& Gross, B. L. (1991). Why we buy what we buy: A theory of consumption values. Journal of Business Research, 22(2), 159-170.

Son, M., \& Han, K. (2011). Beyond the technology adoption: Technology readiness effects on post-adoption behavior. Journal of Business Research, 64(11), 1178-1182.

Spreng, R. A., MacKenzie, S. B., \& Olshavsky, R. W. (1996). A reexamination of the determinants of consumer satisfaction. Journal of Marketing, 60(3), 15-32.

Srite, M., \& Karahanna, E. (2006). The role of espoused national cultural values in technology acceptance. MIS Quarterly, 679-704.

Stewart, G. L., Carson, K. P., \& Cardy, R. L. (1996). The joint effects of conscientiousness and self-leadership training on employee selfdirected behavior in a service setting. Personnel Psychology, 49(1), 143-164.

Szymanski, D. M., \& Henard, D. H. (2001). Customer satisfaction: A meta-analysis of the empirical evidence. Journal of the Academy of Marketing Science, 29(1), 16-35.

Theotokis, A., Vlachos, P. A., \& Pramatari, K. (2008). The moderating role of customer-technology contact on attitude towards technology-based services. European Journal of Information Systems, 17(4), 343-351.
Tett, R. P., Steele, J. R., \& Beauregard, R. S. (2003). Broad and narrow measures on both sides of the personality-job performance relationship. Journal of Organizational Behavior, 24(3), 335-356.

United Nations (2018). Human Development Reports. (accessed October 24, 2018), United Nations Development Programme [available at http://hdr.undp.org/en].

Van der Heijden, H. (2004). User acceptance of hedonic information systems. MIS Quarterly, 28, 695-704.

Van Doorn, J., Mende, M., Noble, S. M., Hulland, J., Ostrom, A. L., Grewal, D., \& Petersen, J. A. (2017). Domo arigato mr. roboto: Emergence of automated social presence in organizational frontlines and customers' service experiences. Journal of Service Research, 20(1), 43-58.

Venkatesh, V. (2000). Determinants of perceived ease of use: Integrating control, intrinsic motivation, and emotion into the technology acceptance model. Information Systems Research, 11(4), 342-365.

Venkatesh, V., \& Davis, F. D. (2000). A theoretical extension of the technology acceptance model. Management Science, 46(2), 186204.

Venkatesh, V., Thong, J. Y. L., \& Xu, X. (2012). Consumer acceptance and use of information technology: Extending the unified theory of acceptance and use of technology. MIS Quarterly, 36(1), 157-178.

Verma, V., Sharma, D., \& Sheth, J. (2016). Does relationship marketing matter in online retailing? A meta-analytic approach. Journal of the Academy of Marketing Science, 44(2), 206-217.

Viswesvaran, C., \& Ones, D. S. (1995). Theory testing: Combining psychometric meta-analysis and structural equations modeling. Personnel Psychology, 48(4), 865-885.

Vize, R., Coughlan, J., Kennedy, A., \& Ellis-Chadwick, F. (2013). Technology readiness in a B2B online retail context. Industrial Marketing Management, 42(6), 909-918.

Walker, R. H., Craig-Lees, M., Hecker, R., \& Francis, H. (2002). Technology-enabled service delivery. International Journal of Service Industry Management, 13(1), 91-106.

Westjohn, S. A., Arnold, M. J., Magnusson, P., Zdravkovic, S., \& Zhou, J. X. (2009). Technology readiness and usage: A global-identity perspective. Journal of the Academy of Marketing Science, 37(3), 250 265.

Wixom, B. H., \& Todd, P. A. (2005). A theoretical integration of user satisfaction and technology acceptance. Information Systems Research, 16(1), 85-102.

Wu, J., \& Lederer, A. (2009). A meta-analysis of the role of environmentbased voluntariness in information technology acceptance. MIS Quarterly, 33(2), 419-432.

Yieh, K., Chen, J. S., \& Wei, M. B. (2012). The effects of technology readiness on customer perceived value. Journal of Family and Economic Issues, 33(2), 177-183.

Zeithaml, V. A. (1988). Consumer perceptions of price, quality, and value: A means-end model and synthesis of evidence. Journal of Marketing, 52(3), 2-22.

Zeithaml, V. A., Parasuraman, A., \& Malhotra, A. (2002). Service quality delivery through web sites: A critical review of extant knowledge. Journal of the Academy of Marketing Science, 30(4), 362-375.

Zhu, Z., Nakata, C., Sivakumar, K., \& Grewal, D. (2007). Self-service technology effectiveness: The role of design features and individual traits. Journal of the Academy of Marketing Science, 35(4), 492506.

Publisher's note Springer Nature remains neutral with regard to jurisdictional claims in published maps and institutional affiliations. 